AperTO - Archivio Istituzionale Open Access dell'Università di Torino

\title{
Crustal strength control on structures and metamorphism in collisional orogens
}

\section{This is the author's manuscript}

Original Citation:

Availability:

This version is available http://hdl.handle.net/2318/1664177

since 2018-11-23T11:48:16Z

Published version:

DOI:10.1016/j.tecto.2017.09.018

Terms of use:

Open Access

Anyone can freely access the full text of works made available as "Open Access". Works made available under a Creative Commons license can be used according to the terms and conditions of said license. Use of all other works requires consent of the right holder (author or publisher) if not exempted from copyright protection by the applicable law. 


\section{Accepted Manuscript}

TEGTONOPHYSICS

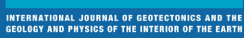

Crustal strength control on structures and metamorphism in collisional orogens

Andrea Piccolo, Manuele Faccenda, Rodolfo Carosi, Chiara Montomoli, Dario Visonà

PII:

S0040-1951(17)30393-1

DOI: doi: $10.1016 /$ j.tecto.2017.09.018

Reference: TECTO 127631

To appear in:

Tectonophysics

Received date:

31 January 2017

Revised date: 11 September 2017

Accepted date: 23 September 2017

Please cite this article as: Andrea Piccolo, Manuele Faccenda, Rodolfo Carosi, Chiara Montomoli, Dario Visonà , Crustal strength control on structures and metamorphism in collisional orogens. The address for the corresponding author was captured as affiliation for all authors. Please check if appropriate. Tecto(2017), doi:10.1016/j.tecto.2017.09.018

This is a PDF file of an unedited manuscript that has been accepted for publication. As a service to our customers we are providing this early version of the manuscript. The manuscript will undergo copyediting, typesetting, and review of the resulting proof before it is published in its final form. Please note that during the production process errors may be discovered which could affect the content, and all legal disclaimers that apply to the journal pertain. 


\title{
Crustal strength control on structures and metamorphism in collisional orogens
}

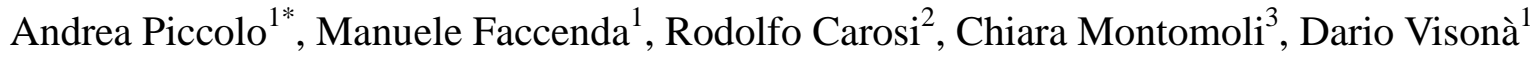 \\ ${ }^{1}$ Dipartimento di Geoscienze, Università di Padova, 35131, Padova, Italy \\ ${ }^{2}$ Dipartimento di Scienze della Terra, Università di Torino, 10125, Torino, Italy \\ ${ }^{3}$ Dipartimento di Scienze della Terra, Università di Pisa, 56126, Pisa, Italy \\ * now at Institute of Geoscience, Johannes Gutenberg-Universitat Mainz
}

\begin{abstract}
Although the upper crust is the most accessible among other crustal units, so far little attention was paid about its role on the continental collision style and on exhumation processes of metamorphic rocks. With this respect, several 2D thermo-mechanical numerical experiments of post-subduction continental collision were performed, which allowed investigating the interplay between surface processes, thermal history and rheology of the upper crust units. The viscous strength of upper and lower plate upper crust (U.U.C. and L.U.C.) was systematically changed, obtaining a reference set of experiments to which subsequently we applied enhanced erosion patterns and variable radiogenic heat productivity of the sediments.

We obtained three classes of collisional style: 1) decoupled asymmetric; 2) coupled asymmetric; 3) coupled symmetric. In general, for high-rates of radiogenic heating, a strong U.U.C. leads to onesided, asymmetric and coupled hot orogen, which shifts to two-sided symmetric for weaker U.U.C.. Lower radiogenic heat productivities yield colder orogens, promoting more asymmetric orogens and eventually the decoupling between upper and lower plates. The enhanced erosion leads to narrower and colder orogens, affecting the collisional style only for a relatively strong L.U.C. rheology.

Exhumation of high-grade metamorphic rocks mainly depends on the L.U.C. strength: a weak viscous rheology promotes pure shear thickening of the incoming crust in the orogenic front, which inhibits both burial and exhumation processes. Higher viscous strengths promote deeper subduction of the L.U.C., with subsequent heating, delamination, partial melting and exhumation of high-grade rocks via channel flow. Enhanced erosion, although not a necessary condition, favours the extrusion of the partially melted mid-crustal channel.
\end{abstract}


Overall, the numerical experiments reproduce the first order structural and/or metamorphic patterns of several natural cases (Himalayas, Boehmian Massif ,Eastern-Central Alps, Apennines) and further suggest that the upper crust rheology is one of the key parameters controlling the collisional style and exhumation processes.

Keyword: Numerical Modelling; Crustal Rheology; Continental Collision; Surface Processes; Radiogenic Heating; Hot Orogens 


\section{Introduction}

Continental collision systems are one of the most impressive and intriguing manifestations of plate tectonics, where the continental crust strongly deforms and several petrological reactions occur. Over the last decades, thanks to the improvement of analytical methodologies, in particular geochronology, the temporal and petrological evolution of collisional orogens has been described more accurately. Nevertheless, as collisional systems are complex tectonic settings where distinct processes (deformation, solid-solid and solid-fluid phase transitions, fluid flow, surface processes, etc.) occur simultaneously, the interpretation of the whole set of geological data is generally difficult. In this respect, numerical simulations allow to integrate several of the main geological processes characteristic of continental collision, offering the opportunity to investigate how they interfere with each other. Several numerical studies have attempted to reproduce active and fossil collisional orogens, highlighting the role that different initial conditions and parameters have in the evolution of the collision zone. For example, it has been shown that the initial thermal structure of the continental crust can potentially change the final style of collision, leading to either a stable (underthrusting) or unstable (thickening) continental subduction and different exhumation patterns of metamorphic rocks (Ge Toussaint et al., 2004; Burov et al., 2014; Sizova et al., 2014) . Surface processes influence the development of shear zones and brittle faults within the foreland basin (Avouac and Burov, 1996; G. Toussaint et al., 2004; Burov and Toussaint, 2007), the stability of continental subduction(Burov and Toussaint, 2007; Burov et al., 2014) and the exhumation of the low viscosity channel inside large hot orogens (Beaumont et al., 2001, 2004, 2006; Jamieson et al., 2004)). Shear and radiogenic heating control the thermal history of the collisional orogeny, and as consequence melt productivity, metamorphic patterns and shear zone localization(Burg and Gerya $\mathrm{T}$. V., 2005; Burg and Schmalholz, 2008; Faccenda et al., 2008). Crustal rheology affects the strength of both lower and upper plates, yielding to different collisional architectures(Faccenda et al., 2008; Burov et al., 2014; Liao and Gerya, 2017). Finally, the convergence rate and the interaction between fluid (melt or water) and solid rocks exert primary controls on the coupling between the plates(Faccenda et al., 2008, 2009; Sizova et al., 2012)

In the present study, we explore the combined effects of the upper crust rheology of both lower and upper plates, radiogenic heat production and surface denudation rates, and show that these parameters have a control over the formation of collisional zones with distinct structural and metamorphic patterns that can be compared with natural cases (Himalayas, Bohemian Massif, the Alps and the Apennines).

Our study focuses mainly on rocks that experienced high-grade metamorphism $\left(>700^{\circ} \mathrm{C}\right)$ and underwent pervasive melting. For this purpose, several numerical experiments were designed to 
reproduce conditions typical of large hot orogens. Following large hot orogens feature high temperatures and pervasive melting of the upper-middle crust, and their tectonic behaviour is mainly characterized by the lateral migration of a low viscosity channel bearing partially melted rocks. The behaviour of large hot orogens was mainly described as a function of the amount of partially melted rocks and their susceptibility to climate forcing. The channel-flow model described by Beaumont et al. (2001) became quite popular over the last years as it seemed to have reproduced the exhumation of the Great Himalayan Sequence (GHS) as a partially melted coherent unit. Recently, this result has been questioned on the basis of geological data highlighting a much more complex evolution of the GHS, which shows a diachronic burial and exhumation history distributed over different sub-units It follows that further investigations on the tectonic and metamorphic evolution of this orogen is required.

\section{Initial Setup}

All the simulations were performed by using the petro-thermo-mechanical code I2VIS(Gerya and Yuen, 2003), which resolves the fundamental equations of continuum mechanics with a conservative finite-difference method and a non-diffusive marker-in-cell technique (see Appendix). The simulations herein described take into account only parametrized solid-melt phase transitions. The mechanical behaviour of the material is simulated with a visco-plastic rheological model.

The computational domain is a rectangular box of 4600x300 km with $\sim 9$ millions Lagrangian particles (Fig. 1). The Eulerian grid is composed by $818 \times 161$ nodes, and the resolution spans between $30 \mathrm{~km}$ to $1 \mathrm{~km}$ and $4 \mathrm{~km}$ to $1 \mathrm{~km}$ along the horizontal and vertical directions, respectively. The highest numerical resolution is set around the collision zone. The initial geometry is made up of three domains: the left continental plate (lower plate) featuring a passive margin with a $10 \mathrm{~km}$ thick sedimentary unit on the right; the central oceanic plate which is partially subducted; the right continental plate (upper plate) which is kept fixed (e.g., The continental crust is composed by a 21 $\mathrm{km}$ thick upper crust (dark and light grey for the lower plate; red for the upper plate) overlying a 15 $\mathrm{km}$ thick lower crust (olive green and dark olive green), while the oceanic crust is composed by a thin layer of sediment ( $2 \mathrm{~km}$, orange) overlying a $7 \mathrm{~km}$ thick layer of mafic rocks (dark green) (Fig.1). The oceanic sediments ensure lubrication along the subduction interface, inhibiting potential deformation within the upper plate during oceanic subduction, thus limiting the parametric space solely to the ones regarding the continental collision, and allowing to develop realistic collisional geometries. Temperature increases linearly within the continental lithosphere from $0{ }^{\circ} \mathrm{C}$ at the top to $400{ }^{\circ} \mathrm{C}$ at Moho depths, and then to $1300^{\circ} \mathrm{C}$ at the lithosphere-asthenosphere boundary. Below the lithosphere we imposed an adiabatic gradient of $0.5^{\circ} \mathrm{C} / \mathrm{km}$. 
In order to reproduce continental collision we prescribed a constant convergence rate of $2.5 \mathrm{~cm} \mathrm{yr}^{-1}$ on the lower plate, which is consistent with the relative convergence between India and Tibet, and Europe and Adria(Guillot et al., 2003; Ader et al., 2012) . A free slip boundary condition is set for the right, left and top boundaries, while the bottom boundary is permeable (Burg and Gerya T. V., 2005; Li et al., 2016). We employed the sticky air approximation (low viscosity layer), which yields a pseudo-free surface boundary condition and allows reproducing topographic evolution during the simulation.

The viscous strength of the continental lower crust and mantle are given by a "mafic granulite" and "dry olivine" flow laws, respectively, while for the upper crust and sediments we used a "wet quartzite" flow law (Ranalli, 1995) that has been modified as explained below. We set a relatively high strength for the lower crust, which was extensively studied by (Faccenda et al., 2008), and low Moho temperatures $\left(400^{\circ} \mathrm{C}\right.$, typical of cratonic crust), as both parameters promote high coupling between the lithospheric mantle and lower crust, and their stable subduction(Gisèle Toussaint et al., 2004; Burov et al., 2014) .

\section{Results}

In order to understand the role of the upper crust rheology on exhumation patterns and on the evolution of post-collisional orogens we have systematically investigated the relative strength between the lower plate upper crust (L.U.C) and the upper plate upper crust (U.U.C). To minimize the number of variables, instead of using different rheological flow laws, we varied the reference viscosity $\eta_{0}=\left[\left(A_{D}\right)^{\frac{1}{n}} * 10^{6}\right]^{n}$ (eq. A.11) of the "wet quartzite" flow law for both the U.U.C. and L.U.C. (see Li et al., 2010), such that it is possible to introduce the parameters $\Omega_{\text {U.U.C. }}=\eta_{0 \_ \text {U.U.C. }} / \eta_{0}$ and $\Omega_{\text {L.U.C. }}=\eta_{\text {O_L.U.C. }} / \eta_{0}$ that express the absolute strength of the two crusts, while their relative strength is given by $\Omega=\Omega_{\text {L.U.C. }} / \Omega_{\text {U.U.C. }}$ For the two upper crusts, we have tested $\Omega_{\text {U.U.C. }}$ and $\Omega_{\text {L.U.C. }}$ values of 1, 10 and 100, simulating a progressively stronger crust where the hard feldspatic phases are more abundant and/or less fluids/volatiles are present. The increase in viscous strength promotes plastic failure over viscous deformation and consequently controls exhumation processes and topography evolution. Also, the maximum topographic height reached by an orogen before the gravitational spreading increases with viscosity of the crust (Pusok and Kaus, 2015). The reference viscosity of the typically wet and weak sediments is kept constant, so that their strength is equal or smaller relative to that of the upper crust. The numerical experiments systematics represent a combination of $\Omega_{\text {U.U.C., }} \Omega_{\text {L.U.C. }}$ and $\Omega$ (9x4 experiments), with the reference set of numerical experiments featuring highly radiogenic $\left(5 \mu \mathrm{W} / \mathrm{m}^{3}\right)$, zircon-rich sedimentary units which normally 
accumulate on craton passive margins(Vidal et al., 1982; Scaillet et al., 1990; Macfarlane, 1992; Beaumont et al., 2006; Faccenda et al., 2008) (Table 1). In addition, in order to investigate the tectonic and metamorphic evolution of colder collisional settings and further compare the results with a broader class of orogens, we also tested cases with low and intermediate radiogenic heat production (Table 4).

The effects of surface processes are explored in 9 additional experiments by varying the rate of erosion across the collisional orogen. We applied enhanced denudation rates acting on the flank of the mountain range facing the foreland basin, simulating fast erosion typical of tropical areas (e.g., Beaumont et al., 2001; see Appendix). The sedimentation rate is held constant, implicitly assuming an efficient redistribution of sediments by riverine transport perpendicular to the modelled 2D section.

\subsection{Reference set of Experiments: Effects of the U.U.C and L.U.C strength in hot orogens.}

The style of collision and metamorphic rock exhumation is affected by both the relative and absolute viscous strength of the L.U.C. and U.U.C. (Fig. 2 and Fig. S.2). In this set of numerical experiments, the erosion rate is kept constant and is active only if the surface topography is above the sea level. The rate of erosion is low $\left(0.312 \mathrm{~mm} \mathrm{yr}^{-1}\right)$ and topography is reduced mostly by gravitational spreading. It is possible to distinguish two broad classes of collisional styles that differ for the flow direction of the L.U.C. material and the integrity of the upper plate: symmetric and asymmetric (Fig.2). The principal characteristics are:

- Symmetric style orogens features unidirectional material flow, in which the material of the L.U.C. intrudes into the upper plate in between the upper and lower crust. Intrusion is accommodated by the downward flexure of the upper plate lithospheric mantle, which results in a double-vergent orogen. In general, these numerical simulations are associated with the development of a wide orogenic plateau.

- Asymmetric style (or wedge shaped, following (Vanderhaeghe, 2012)) orogens features a bidirectional material flow, in which the L.U.C. material stops near the suture area (here defined as the limit between upper and lower plate material) and then is forced to change its direction towards the lower plate foreland due to the high strength of the upper plate acting as a backstop. As a consequence, the upper plate experiences a limited deformation due to its high viscosity. In case of low L.U.C. viscosity, the incoming material thickens through pervasive and diffusive deformation and partially melted rocks tunnel within the thickened area. On the other hand, an incoming L.U.C. with high viscosity experiences a corner flowlike circulation, which yields to an initial upward exhumation of high P-T metamoprhic 
rocks during the initial stage, and subsequently to a horizontal flow between the underthrusting continental crust, and the rigid plastic cold layer at the top. This behaviour resembles the conceptual model described in (Platt, 1986, 1993).

In absence of enhanced erosion, the necessary condition for developing asymmetric orogens relies on the U.U.C. strength that must be able to bear the stresses arising during the collision (Faccenda et al., 2008, 2009; Warren et al., 2008). As shown in Fig.2, this condition requires high values of $\Omega_{\text {U.U.C. }}=100$. Burial and exhumation processes depends mainly on the L.U.C. strength, but in some particular cases even the rheology of the U.U.C. has a key role (e.g., in K7 ( $\left.\boldsymbol{\Omega}_{\text {U.U.C. }}=\mathbf{1}, \boldsymbol{\Omega}_{\mathbf{L . U . C} .}=\mathbf{1 0 0}\right)$ and K8 $\left(\mathbf{\Omega}_{\mathbf{U . U . C}}=\mathbf{1 0}, \boldsymbol{\Omega}_{\mathbf{L . U . C .}}=\mathbf{1 0 0}\right)$, respectively; see Fig.S2).

Two representative experiments for both symmetric and asymmetric cases will be briefly described to highlight the effects of the relative and absolute strength of both U.U.C. and L.U.C.:

K2 $\left(\Omega_{\text {U.U.C. }}=10, \Omega_{\text {L.U.C. }}=1\right)$, symmetric: during the incipient stages of the collision, the passive margin sediments are detached from the underthrusting continental plate and accreted to the collisional margin, forming a thick and highly radiogenic crust that starts melting at about $15 \mathrm{~km}$ below the surface (yellow and brown-yellow; see Fig.1 for further details). The partially melted crust migrates toward the pro-foreland at mid-crustal depths facilitating the detachment and overthrusting of the incoming upper crust (Fig.3 a-b). At the same time, the partially melted material slowly migrates towards the retro-foreland and, after the bending of the upper plate, starts tunneling through the U.U.C. forming a plateau (Fig.3 c-d). This mode of collision continues till the end of the simulation. The distribution of partially melted rocks and the position of the orogenic plateau shifts toward the pro-foreland with increasing $\Omega_{\text {U.U.C., }}$ reflecting a stronger resistance to deformation of the upper plate (see Fig.2, in particular K1 and K2). The exhumed rocks register low-to-medium peak metamorphism (2-5 kbar, 200-500 $\left.{ }^{\circ} \mathrm{C}\right)$, and no high-grade metamorphic rocks are exhumed to the surface (Fig.4a-b). The exhumation is mainly driven by the melt buoyancy and by the erosion, which is low and constant through all the orogen. As such, the partially melted layer remains thermally insulated by the overlying low-grade rocks and its thickness progressively increases.

K7 $\left(\Omega_{\text {U.U.C. }}=1, \Omega_{\text {L.U.C. }}=100\right)$, symmetric: During the initial stages of the collision, the orogen is asymmetric, with the lower plate capable of supporting collisional stresses, and high-grade metamorphic rocks that are extruded via corner-flow within the lower plate (Fig.5 a-b). Subsequently, the relatively weak U.C.C. starts deforming and thickens in two distinct phases: an initial phase of intrusion and tunneling of the partially melted material, followed then by the 
overthrusting of the L.U.C. material over the U.C.C. that generates a symmetric orogen with extrusion of high grade rocks (which achieve a temperature $\mathrm{T}>700^{\circ} \mathrm{C}$ during the metamorphic peak)in both flanks of the plateau. As collision continues, the hot L.U.C. migrates progressively toward the retro-foreland causing an asymmetric distribution of the partially melted material (Fig. $5 c-d)$. On the other hand, if the strength of the U.U.C. is higher, the partially melted rocks redistribute symmetrically across the inner part of the orogen (Fig.2, $\mathbf{K 8}\left(\boldsymbol{\Omega}_{\text {U.U.C. }}=\mathbf{1 0}, \boldsymbol{\Omega}_{\text {L.U.C. }}=\mathbf{1 0 0}\right)$, in particular). The exhumed rocks show homogeneous high temperature $\left(\sim 650-700{ }^{\circ} \mathrm{C}\right)$, and the peak temperature is achieved at low-intermediate pressures (Fig.6 a-b). Only during the initial stage of the collision the high temperature rocks record high pressures (see Fig. 6b and Fig 6e). The timing of the metamorphic peak systematically increases toward the retro-foreland (Fig. 6c). The preferential migration of the hot materials toward the upper plate has implication on exhumation processes, tectonic processes and topography evolution (see Fig. 5 b-d, Fig 6f). In particular the foreland basin initially migrates toward the lower plate direction, then toward the upper plate direction.

Test K6 $\left(\Omega_{\text {U.U.C. }}=10, \Omega_{\text {L.U.C. }}=100\right)$, asymmetric: (Fig.7) high-grade metamorphic rocks are extruded via channel flow in the lower plate flank of the orogen during the initial stages of the continental collision. Subsequently, diffusive buckling takes place within the incoming upper crust which then is overthrusted above the partially melted channel. The processes of exhumation is inhibited, and the only rocks displaying peak metamorphism at high temperatures $\left(650-700{ }^{\circ} \mathrm{C}\right)$ and moderate-tohigh pressures are localized in the inner part of the plateau (Fig.8c).

Test K9 ( $\left.\Omega_{\text {U.U.C. }}=100, \Omega_{\text {L.U.C. }}=100\right)$, asymmetric: (Fig.9) both L.U.C. and U.U.C. are strong enough to bear the collisional stresses. The L.U.C. is under-thrusted at high-depths down to the suture area where it decouples from the lower crust and experiences pervasive partial melting. The buoyant partially melted rocks move toward the lower plate foreland, being channelized between the cold and rigid top of the orogenetic building, and the incoming L.U.C.. The channel flow that is generated in such conditions persists through the remaining part of the simulation, and the exhumation of high-grade metamorphic rocks is achieved both in the plateau and in the orogenic front (see Fig. $10 \mathrm{~d}$ and f). During the lateral migration of the hot channel, the uppermost part of the orogen locally experiences extensional deformation that migrates toward the foreland, aiding the exhumation of high-grade domes. The partially melted rocks migrate at depths through a linear and non-chaotic channel flow that accommodates most of the convergence. The peak temperature is reached during exhumation, which can be divided in two stages (see Fig. 9 a-d): 1) Heating and 
decompression; 2) quasi-isobaric cooling. The increase of temperature during the decompression is a consequence of shear heating, due to the high strain rate of the weak partially melted area. The peak pressure recorded by exhumed rocks decreases from the suture area towards the lower plate foreland (e.g., The rocks displaying the highest peak pressure $\left(20 \mathrm{kbar}, 650-700{ }^{\circ} \mathrm{C}\right)$ are exhumed during the initial stages of the collision (30-40 Myrs), while those exhumed at later stages record progressively lower peak pressures (Fig.10b,e). The velocity of the partially melted rocks varies along the horizontal direction, ranging from 3 to $7 \mathrm{~cm} \mathrm{yr}^{-1}$ (i.e., 1.2 to 2.8 times the convergence rate).

\subsection{Effect of enhanced erosion}

Each experiment of the reference set was performed again applying enhanced erosion on the orogenic front (Table 3). The enhanced erosion is active in an area limited by the foreland topographic minimum and the maximum height achieved by the orogeny (see Table 3 and Section A4 in Appendix). Enhanced erosion promotes the exhumation of high pressure metamorphic rocks (peak P $\sim 20 \mathrm{kbar}$ ) near the suture zone. Furthermore, it affects the style of the collisional orogen (e.g., K7strong $\left(\boldsymbol{\Omega}_{\text {U.U.C. }}=\mathbf{1}, \boldsymbol{\Omega}_{\text {L.U.C. }}=\mathbf{1 0 0}\right)$ and K8strong $\left(\boldsymbol{\Omega}_{\mathbf{U . U . C}}=\mathbf{1 0}, \boldsymbol{\Omega}_{\mathbf{L . U . C} .}=\mathbf{1 0 0}\right)$ ), that passes from being symmetric to asymmetric due to the removal of the accreted material in the foreland (Fig.11, Fig.S.3). Erosion exerts an indirect control on the thermal state of the orogen: it removes material reducing the thickness of crust (limiting the effect of the radiogenic heat production) and cools the orogen generating fast exhumation of the hotter inner part of the orogen. As a consequence, the amount of melt is significantly lower with respect to the reference set of numerical experiments (Fig.2 and Fig.11). As erosion rates linearly increase with the height $(\mathrm{H}, \mathrm{km})$ of the orogen, the cooling effect increases with $\Omega_{\text {L.U.C }}$, the strength of the orogen. Next, we briefly describe the evolution of one representative model displaying such asymmetric orogen:

K7strong $\left(\boldsymbol{\Omega}_{\text {U.U.C. }}=\mathbf{1}, \boldsymbol{\Omega}_{\text {L.U.C. }}=\mathbf{1 0 0}\right)$ : Similarly to his reference counterpart $(\mathrm{K} 7)$, the initial part of the simulation is characterized by the accumulation of the sediments from both the oceanic plate and the passive margin. Subsequently, a partially melted channel forms and extrudes in the lower plate foreland. The collisional orogen is narrower than the counterpart without enhanced erosion. Temperatures are lower, and the amount of melt produced is limited within the orogen (Fig.12 a-d). Despite this, the exhumed crustal units record high temperatures. The youngest rocks are exhumed near the suture zone and register the peak temperature at high pressures $\left(650-700{ }^{\circ} \mathrm{C}, 24-25 \mathrm{kbar}\right.$, Fig.13a and Fig.13d), while older rocks are exhumed mainly in the lower plate flank of the orogen (600-650 ${ }^{\circ} \mathrm{C}, 10-12$ kbar; Fig.13b,e ). 


\subsection{Radiogenic Heat Production}

We tested the effect of low radiogenic heat production by decreasing $\mathrm{H}_{\mathrm{r}}$ of the sedimentary rocks from $5 \mu \mathrm{W} / \mathrm{m}^{3}$ to 3.5 or $1.5 \mu \mathrm{W} / \mathrm{m}^{3}$. As for the reference set of experiments, the erosion rate is low and constant. Lowering these values has several first order effects on the numerical experiments.

$H_{r}=1.5$ : There are two modes of collision (both asymmetric) depending on the L.U.C. strength: coupled and decoupled (i.e., Most of the numerical experiments are in the latter category, and are characterized by a high or intermediate value of $\Omega_{\text {L.U.C. }}$ On the other hand, the experiments with the lowest viscosity contrast $\left(\Omega_{\text {L.U.C. }}=1\right)$ exhibit a coupled, asymmetric collisional style with low production of partially melted rocks and no exhumation of high-grade metamorphic rocks (Fig.14 and Fig. S4). The evolution of a fully decoupled collisional orogen results in a complex pattern of exhumation. This can be seen for example in test $\mathbf{K} \mathbf{4}_{\mathbf{r 1}}\left(\boldsymbol{\Omega}_{\text {U.U.C. }}=\mathbf{1 0}, \boldsymbol{\Omega}_{\text {L.U.C. }}=\mathbf{1}\right)$ (Fig.15), where the lower plate decouples from the upper plate and starts to rollback after the onset of the continental collision. Slab rollback triggers massive upwelling of the asthenosphere that is in direct contact with the orogenic building (see Fig. 16a,b). As a consequence, heat flow increases, triggering melting of the lower orogenic crust which starts to move upward forming a dome of high-grade metamorphic rocks (750-800 $\left.{ }^{\circ} \mathrm{C}, 10-20 \mathrm{Kbar}\right)$. The mixing of cold and hot material yields a complex metamorphic surface pattern featuring several tectono-metamorphic discontinuities (see Fig. 17a,b,d,f). The L.U.C. experiences crustal scale faulting with blocks that are piled in the orogenic front. The burial and exhumation processes are complex: the high deformation in the frontal part of the orogen and the continuous extension in the adjacent crustal units produce highly diachronic metamorphism (Fig. 17c).

$H_{r}=3.5$ : the experiments with low $\Omega_{\text {L.U.C }}$ feature the same characteristics as those of the reference set of tests (Fig. 2), except for delayed U.U.C deformation, production of partially melted rocks and timing of metamorphic rock exhumation (Fig.15 and Fig. S5) (Faccenda et al., 2008). Intermediate L.U.C. strength shifts the mode of collision from fully decoupled to asymmetric style (Figs. 14 - 15).

\section{Discussion}

In our numerical experiments we have not considered separation of the melt phase from the solid matrix, which would affect the rheological behaviour and the buoyancy of the extruding mid-crustal channel (Gerya et al., 2008; Faccenda et al., 2009; Sizova et al., 2010, 2014; Gerya and Meilick, 2011; Vogt et al., 2012). Furthermore, melting reactions are parameterized (Table 2), while a self- 
consistent approach where the physical properties and melt fraction of stable mineral aggregates are computed as a function of the local P-T conditions (e.g., (Connolly, 2005, 2009)) is envisaged for future developments of the present study. Although displaying different viscous behaviors in several tests, the upper crust of the upper and lower plates is assumed to be homogeneous, neglecting structural and compositional heterogeneities that could affect both metamorphic and tectonic patterns(Reuber et al., 2016). The employed numerical domain and the permeable bottom boundary condition do not allow reproducing slab interaction with major phase transitions of the mantle (Faccenda and Dal Zilio, 2017) and/or slab breakoff which has been shown to be important when studying exhumation processes(Duretz et al., 2011) .

Taking into account these limitations, our results give numerous insights for deciphering metamorphic patterns in collisional orogens. When the upper crust is weak, the high-grade metamorphic rocks starts tunnelling beneath the thickened crust, and they remain thermally insulated from the cold surface, leading to a thickening of the partially molten layer and no exhumation. This promotes gravitational instabilities and small-scale convective currents within the hot channel that super-impose over the large-scale lateral migration toward the upper and lower plates (e.g., Test K2, Fig. 3, and Test K6, Fig.6). These results are consistent with those of where the deformation of the upper plate and associated shift of tectonic and metamorphic activity toward the upper plate occurred mainly when using a weak lower crust rheology (wet quartzite flow law). Asymmetric collisional zones associated with strong-intermediate L.U.C. rheology features a crustal flow pattern that resembles the corner flow model of (Platt, 1993),promoting the exhumation of high-grade metamorphic rocks. Such material circulation occurs when the upper plate acts as an efficient backstop (K7-K9, Fig.6a,b and Fig.10a,b), and a continuous mode of exhumation is obtained when enhanced erosion is applied (Fig.13). Orogenic spreading during the ongoing collision is driven mostly by the partially melted rocks that absorb all the deformation and propagate the structure toward the lower plate.

The numerical experiments with high radiogenic heating of the passive margin sedimentary rocks were designed to explore the evolution of Phanerozoic hot orogens (i.e., Himalaya), and are not representative of Proterozoic-Archean hot orogens (e.g. (Sizova et al., 2014, 2015) or ultra-high temperature orogens (Chardon et al., 2009) that require a hotter lithosphere and/or a pervasive interaction between mantle magmatic processes and juvenile continental crust production. Our results are directly comparable with the numerical experiments provided by (Beaumont et al., 2001, 2004, 2006) and (Jamieson et al., 2004)which however are crustal scale kinematic models that do not take into account an initial oceanic subduction stage (responsible for the formation of a precollisional subduction margin and accretionary prism) and where the continental crust is forcibly 
subducted down to the middle of the orogen. In our models the collisional orogen progressively thickens, displaying an asymmetric evolution of the metamorphism and deformation toward the lower plate that can eventually become symmetric with a progressive shifting of the deformation and exhumation towards the upper plate. In the latter case, the partially melted material preferentially tunnels the upper plate and we observe a continuous redistribution of material between the two plates (e.g. K1-K2, K4-K5, Fig.2). The numerical experiments with crustal channel flow are analogous to the result by (Beaumont et al., 2001, 2004, 2006)and (Jamieson et al., 2004), reproducing a similar topographic evolution, but differ with respect to the metamorphism. When the incoming L.U.C. crust is weak, the channel flow does not exhume toward the surface even when applying a strong surface erosion in the foreland flank of the orogen. We observe a thickening of the partially melted layer with time and development of convective motions inside that area. On the other hand, the numerical experiments with a strong L.U.C. display channel flow eventually extruding at the surface and thus exhuming large amounts of high temperature rocks with metamorphic peak conditions of $\mathrm{T}=650-700{ }^{\circ} \mathrm{C}, \mathrm{P}=6-10 \mathrm{kbar}$.

The effect of enhanced and focused erosion changes with the upper crust rheology, and in general favours cooling and narrowing of the orogen. For a weak or intermediate L.U.C. viscous rheology, enhanced denudation rates promote exhumation of high-grade rocks near the suture zone, and medium-grade rocks in the lower plate flank of the orogen. When the rheology of L.U.C. is strong, the overall architecture of the orogeny switches from symmetric to asymmetric as the accreting material is efficiently removed (compare tests $\mathrm{K} 7-8_{\text {strong, Fig. }}$ 11, with K7-8, Fig. 2), creating wellorganized patterns of metamorphic rock exhumation both in space and time.

The radiogenic heat productivity controls the thermal structure of the orogen and its rheological behaviour, shifting the modes of collision from fully decoupled orogens toward double sided hot orogens with increasing $H_{r}$. This transition is systematic: the decoupling between the upper and lower plate is usually associated with weakening of the subduction channel due to the insertion of relatively weak upper crustal material (e.g.,(Faccenda et al., 2009)). Conversely, when the crustal prism is hotter, the upper crust is weaker and more easily detached from the subducting lower plate before entering the subduction channel. Thus, the radiogenic heat productivity has a first order control on the final style of the collisional orogen.

The evolution of our experiments resembles the conceptual model drawn by (Vanderhaeghe and Teyssier, 2001; Vanderhaeghe, 2009, 2012). During the initial stage of continental collision, a thick orogenetic root forms near the suture zone, which undergoes pervasive melting. As function of the rheology and radiogenic heating there are possible paths that the collisional system can follow. The first case features coupled collisional orogens and the collapse by gravitational spreading during the 
ongoing collision, with lateral migration of the partially melted material and the crust that distributes over a wider area. In the second case, the initially thick orogeny is thinned by decoupling of the upper and lower plates, followed by slab rollback and asthenosphere upwelling. Decoupling is promoted by the insertion of relatively weak crustal material within the subduction channel, which is then intruded by theasthenospheric mantle. The thermal history of the orogen is controlled mainly by the internal heat production in the first case, while in the latter case by the heat flux from the asthenosphere.

\subsection{Comparison with natural orogens}

The numerical experiments are here compared with natural orogens. Despite this study mainly focuses on the tectonic and metamorphic evolution of large hot orogens, we will also discuss other natural cases with a colder thermal structure.

4.1.1 Himalayas: The Himalayan range is the product of the collision between India and Eurasia, and features a complex tectono-metamorphic history(Yin and Harrison, 2000; Yin, 2006). The India-Asia collision occurred about 50 Myrs ago (Capitanio et al., 2010; van Hinsbergen et al., 2011; Jagoutz et al., 2015), with the Indian plate that is currenty moving northward at rates of 4-5 $\mathrm{cm} \mathrm{yr}^{-1}$ (Copley et al., 2010). However, as the Indian plate is indenting Asia, the relative velocity between India and south Tibet is $1.7-2.5 \mathrm{~cm} \mathrm{yr}^{-1}$ (Guillot et al., 2003; Ader et al., 2012), which is consistent with convergence rate adopted in our simulations. The high-grade metamorphic rocks were subjected to high temperatures $\left(\sim 70{ }^{\circ} \mathrm{C}\right)$ and partial melting(Imayama et al., 2012; Montomoli et al., 2015; Iaccarino et al., 2016). These rocks are confined within the GHS that is bounded by two major discontinuities: the South Tibetan Detachment on the north and the Main Central Thrust on the south (Hodges, 2000; Yin and Harrison, 2000; Yin, 2006). Over the last decades, several exhumation models were proposed to explain the exhumation of these high-grade migmatitic rocks (Grujic et al., 1996; Nelson et al., 1996; Chemenda et al., 2000; Beaumont et al., 2001; Kohn, 2008; Montomoli et al., 2015). One of the most popular model consider the GHS as a coherent unit that exhumed from deep crustal levels by channel flow. This type of flow would be driven by lateral pressure gradients that forms in response to the highly focused erosion on the southern flank of the Himalayas (Beaumont et al., 2001). This paradigm was recently questioned by (Kohn, 2008; Iaccarino et al., 2015; Wang et al., 2015; Carosi et al., 2016) that have highlighted the highly diachronic exhumation patterns of the metamorphic rocks and the existence of several tectono-metamorphic discontinuities within the GHS. The new exhumation model proposed for the GHS requires continuous under-thrusting of different slices of Indian continental crust, which 
progressively experience burial, partial melting and exhumation at the surface as high-grade metamorphic rocks(Montomoli et al., 2015; Carosi et al., 2016) . Exhumation occurs at first near the South Tibetan Detachment, and subsequently shifts toward the Indian foreland with crustal units displaying lower P-T metamorphic peaks. This leads to the activation of several shear zones with progressive younging of the deformation toward the Indian plate.

Albeit our simulations could not resolve entirely such a complex structural pattern, the models characterized by an asymmetric collisional zone in conjunction with strong erosion mimic several of the observed features, i.e. (i) the emplacement of an inverted metamorphic sequence with highgrade metamorphic rocks thrusted above low-grade material, (ii) the presence of a partially melted channel to mid-crustal depths as indicated by bright seismic reflectors (Nelson et al., 1996) which occasionally exhume at the surface with extension and doming (Fig.10, Fig 13, Fig18). In principle, all the numerical experiments that show channel flow of the partially melted material could be representative of the Himalayan range. However, there are several differences that could be not yet resolved. Asymmetric collision zones without strong erosion are characterized by a higher (in case of high L.U.C. viscosity) or a wider (in case of low L.U.C. viscosity) orogen with respect to the Himalayan belt. The numerical experiments that experience long lasting channel flow present a wide orogenic plateau with a homogeneous metamorphic pattern, e.g. Test K9 and Test K6. On the other hand, the numerical simulations with surface metamorphic patterns similar to those recorded in the Himalayan range (e.g. K1, K2 and K3, and their twin experiments with applied enhanced erosion) do not feature the exhumation driven by channel flow. Furthermore, the displacement of the hot partially melted rocks seems to be insensitive to the enhanced erosion. This could be the consequence of our relatively low erosion rates, but as pointed out by (Yin, 2006), the erosion rate employed by (Beaumont et al., 2001) is too high when compared to the available data (below 1 $\mathrm{mm} / \mathrm{yr})$.

In our numerical experiments, the exhumation is more coherent and the diachronic pattern is not reproduced. This poses several questions on what are the conditions to generate extrusional shearzones that drive the diachronic exhumation processes, and which is the proper length scale to address such problem. Our simulations, although not fully representative of the Himalayan range evolution, indicate that the focused enhance erosion on the orogenic front that is often invoked to explain the exhumation of the GHS (Beaumont et al., 2001, 2004; Jamieson et al., 2004) is not a necessary condition, while the rheology of the upper crust seems to exert first order controls on the metamorphic patterns.

\subsubsection{Bohemian Massif}


The Bohemian massif is one of the products of the Paleozoic Varisican Orogeny (400-300 Ma). The Varisican Orogeny was the consequence of the convergence between Gondwana and Laurasia plates, whose margins were a complex collage of continental and oceanic domains. In such scenario, the Bohemian massif was the result of the convergence between two continental domains within this plates framework (Schulmann et al., 2009, 2014; Kroner and Romer, 2013).

The history of the Bohemian massif started during the Devonian with the subduction of the SaxoThuringian ocean beneath the Teplà-Barrindian terrain (a small and thinner transitional domain of the eastern Brunia microplate) in the western area of the Bohemian massif. The eastern verging subduction of the oceanic plate triggered magmatism generating a small magmatic arc, with associated a thinner back arc domain (Teplà-Barrindian terrain, Moldanubian domain) (Schulmann et al., 2009, 2014). During the collision of the Saxo-Thuringian and the Teplà-Barrindian continental terrains, the continental crust was subducted to high depths reaching pressures of 20-25 kbar and temperatures $>800{ }^{\circ} \mathrm{C}$. After their burial, these rocks rose and relaminated at the base of the Teplà-Barrindian terrain. Such hot material started to intrude and spread laterally within the upper plate as a consequence of its low viscosity (Schulmann et al., 2009, 2014). The orogenic wedge is subsequently indented by the eastern Brunia microcontinent producing a multiscale folding of the orogenic infrastructure and exhumation of the hot Saxothuringian material with different mechanisms. In the south, both the lower and middle orogenic crust were exhumed by diapirism in the inner area of the Moldanubian domain, and by channel flow directed toward both the Brunia continent and the Saxo-Thuringian suture (Schulmann et al., 2008; Franěk et al., 2011). In the northern area, exhumation occurred with the rising of a granulitic dome (the Orlica-Śnieżnik gneissitic unit) against the Brunia lithosphere that acted as a backstop (Chopin et al., 2012)).

Despite our numerical models are not fully representative of the complex scenario and geometry characterizing the Bohemian Massif, they can be helpful to understand the processes of mass transfer between the lower and upper plates. The stable subduction of the continental crust down to mantle depths is indicative of a strong L.U.C., which can experience high pressure (18 kbar) and high temperatures $\left(>700{ }^{\circ} \mathrm{C}\right.$ ) conditions (e.g., K7, fig 5-6). Subsequently, these rocks tend to rise thanks to the buttress offered by the upper plate lithospheric mantle and to the buoyancy related to the presence of melt. If the upper plate crust is relatively weak, the high metamorphic grade material starts to intrude and migrate laterally through the upper plate. The relative propagation of the material within the upper plate is controlled by the strength of the U.U.C.. Our experiments indicate that the deep granulites can be transferred toward the upper plate thanks to the melt weakening effect. The exhumation of the high-grade rocks associated with the indentation of the stiff Brunia micrcontinent could not be reproduced in detail, as this would require a heterogeneous 
U.U.C. composed by a thin and weak portion (the Devonian backarc, arc and forearc crust) juxtaposed with a strong unit (the Brunia microcontinent). Nevertheless, such an exhumation process can be seen in models with a stiff U.C.C. (e.g., K9, Fig. 9-10), where the stiff upper plate forces the upwelling of high-grade metamorphic rocks toward upper-middle crust depths.

4.1.3 Eastern and Central Alps: Alps tectono-metamorphic history is complex both in space and time. The collisional style and the geometry of the orogen systematically change from the west to the east, as a function of the coupling between upper and lower crust of the upper plate(Rosenberg et al., 2015; Rosenberg and Kissling, 2013; Liao and Gerya, 2017). The different collisional styles are also characterized by different metamorphic and exhumation patterns: high-pressure rocks are extensively exhumed in the western portion of the collisional chain where the lower crust of the Adria margin is steeply dipping and likely acted as a backstop for the incoming crust of the European plate. Medium-grade metamorphic overprint widely affects units in the central Alps where the Adria crust overthrusted the European plate (e.g.,(Burg and Gerya T. V., 2005) ).

Following (Rosenberg et al.,2015.; Rosenberg and Kissling, 2013), the along-strike variability of the Alpine collisional zone could be interpreted as due to variations in the viscous strength of L.U.C.. Here we further suggest that even differences on the strength of the Adrian Plate (U.U.C.) could likewise explain this structural and metamorphic variability (except for the Western Alps).

The numerical experiments with low L.U.C. and U.U.C. viscosity and medium to high $\mathrm{Hr}$ of the sediments could be representative for the more symmetric structure of the eastern-central Alps (i.e., $\mathrm{K} 1-\mathrm{K} 2, \mathrm{~K} 1_{\mathrm{r} 2}-\mathrm{K} 2_{\mathrm{r} 2}$, Fig 2,3,4). The U.U.C. strength controls the collisional strain partitioning between the two plates and the eventual tunnelling of L.U.C. materials through the upper plate. As such, a weaker U.U.C. in the eastern-central Alps could explain the intruding European crust within the Adria crust . A relatively weak L.U.C. causes thickening of the crust since the initial stage of continental collision which inhibits the burial and exhumation processes (e.g. K1, see Fig.3-4): in that case, the metamorphism of the surface rocks records regional heating caused by the hot interior of the orogen. The degree of regional metamorphism depends on the radiogenic heat production, and as consequence the recorded peak temperatures in $\mathrm{K} 1_{\mathrm{r} 2}$ and $\mathrm{K} 2_{\mathrm{r} 2}$ (350-400 C, 4-5 kbar) are lower than in the reference set of experiments.

4.1.4 Northern Apennines: this mountain chain formed in response to the subduction of the Adria plate's western margin. Over the last 25-30 Myr, the Adria plate rolled back toward the east, leading to the eastward migration of the Apenninic range and to the opening of the Tyrrhenian basin where the thinned and delaminated upper crust of Adria was interested by magmatism and exhumation of 
high-grade metamorphic rocks(Jolivet et al., 1998; Brun and Faccenna, 2008; Vignaroli et al., 2009) . Nowadays, the compressional front is located in the Po plain and along the Adriatic coast, while extensional tectonics is active within the mountain range and is characterized by high- and low-angle normal faults that dissect older sets of thrusts(Collettini and Barchi, 2004; Pauselli et al., 2006) .

The fully decoupled numerical experiments obtained with low radiogenic heat productivity of the passive margin sediments well reproduce the Northern Apennines tectonic evolution, in particular $\mathrm{K} 4_{\mathrm{r} 1}$. This is consistent with the cold thermal structure of the orogen(Pauselli et al., 2006), which could reflect the evaporitic and calcareous (low contents in radiogenic elements) thick sedimentary units that have accumulated over the Adria plate during the Mesozoic and Cenozoic (Speranza and Chiappini, 2002; Carminati et al., 2013). The model results are also consistent with decoupled collision systems described in (Faccenda et al., 2009), and show a lateral migration of the mountain chain followed by the collapse of the adjacent delaminated upper crust. The inner domain features low lithospheric thickness, asthenospheric upwelling, continental magmatism, and exhumation of high-grade metamorphic rocks due to extensional deformation, while the foreland domain is much colder and displays a series of thrusts that facilitate upper crust delamination.

\section{Conclusions}

We systematically varied the viscous strength of upper and lower plate upper crust, the radiogenic heat productivity of the sediments and the efficiency of surface denudation processes to explore their relative contribution on both the style of collision and exhumation patterns of metamorphic rocks. The main results can be summarized as follows:

1) the viscous strength of the U.U.C. controls the strength of the upper plate and the efficiency of the propagation of L.U.C. material through it. A relatively weak upper crust favours the migration of partially melted L.U.C. material towards the upper plate producing a wide orogenic plateau.

2) the viscous strength of the L.U.C. is the most important factor controlling the exhumation of high-grade metamorphic rocks both in the inner portions of the orogenic plateau and along its flanks. High viscous resistance prevents diffusive crustal thickening in the lower plate, and promotes stable under-thrusting of L.U.C. down to the orogenetic prism. Channel flow-like behaviour of the partially melted L.U.C. can be a short-lived or continuous feature: the short-live channel flow extrusion usually stops as soon as the L.U.C. crust starts thickening by diffused deformation in the pro-foreland. This inhibits the burial and exhumation of incoming L.U.C. and insulates the partially 
melted rocks from the external environment. The result is a thickened and cloudy-shaped partially melted area dominated by small-scale convective currents.

3) Enhanced erosion favours the exhumation of high-grade metamorphic rocks, limits the amount of L.U.C. materials intruding the upper plate and results in smaller orogens.

4) High radiogenic heat production of passive margin sediments is crucial for the formation of hot orogens. By increasing radiogenic heating there is a systematic shift of the collision modes from fully decoupled to symmetric orogenic styles. Low radiogenic heat production and intermediatestrong L.U.C. rheology promote decoupling even at low convergence rates.

5) The experiments featuring asymmetric collisional style and extrusion of high-grade metamorphic rocks are suitable for comparison with the Himalayan range. However, the sequential burial and exhumation of these rocks along several regional scale shear zone (e.g. High Himalayan Discontinuity) as recently described could not be reproduced in detail. We interpret this discrepancy as due to the employed numerical resolution $(1 \mathrm{~km})$ and to other un-accounted for localization processes. Nevertheless, our numerical experiments show that one of the paramount condition to achieve channel flow-like behaviour and exhumation of high-grade metamorphic material is the constant and stable under-thrusting of the continental crust, subsequent detachment and partial melting at depths. Focused erosion is not strictly necessary for exhumation at the surface of the high-grade metamorphic rocks.

6) Our numerical experiments give insights about the mass transfer between upper and lower plates in hot orogens, which is a process that shaped the Bohemian massif. Furthermore, the exhumation of the Orlica-Śnieżnik dome is consistent with that observed in models characterized by a stiff U.C.C., providing a coherent framework through which is possible to generate the conditions of exhumation of granulite facies within the dynamics of a wedge shape orogen.

7) Results from models with a low to intermediate radiogenic productivity (yielding colder and stiffer orogens) account for the high variability of the Phanerozoic collisional styles observed on Earth (e.g., Alps and Apennines), highlighting the role of the upper crust strength and thermal evolution on the overall evolution of the orogenetic system. 


\section{$\underline{\text { Appendix }}$}

\section{A1. Fundamental equations}

\section{A.1.1 Stokes and Continuity Equations}

The conservation of mass and momentum equations are solved together using the Boussinesq approximation. Hence, the continuity equation is:

A.1) $\frac{\partial v_{x}}{\partial x}+\frac{\partial v_{z}}{\partial z}=0$

where $\mathrm{v}_{\mathrm{X}}$ and $\mathrm{v}_{\mathrm{Z}}$ are the component of the velocity field.

The Stokes equation can be expressed in the following way (we used the Einstein notation):

A.2) $\frac{\partial \sigma^{\prime} \mathrm{ii}}{\partial i}+\frac{\partial \sigma_{\mathrm{ij}}^{\prime}}{\partial j}-\frac{\partial P}{\partial i}=-\rho(\mathrm{C}, \mathrm{T}, \mathrm{P}, \mathrm{M}) g_{i}$

where $\sigma_{\mathrm{ij}}^{\prime}$ is the $\mathrm{ij}$ component of deviatoric stress tensor, $\mathrm{P}$ is the total dynamic pressure, $\mathrm{g}_{\mathrm{i}}$ is the gravity acceleration component along the considered direction. The rock density depends on the chemical composition, temperature, pressure and the volumetric degree of melting. The solid rock density is:

A.3) $\rho(\mathrm{T}, \mathrm{P})=\rho_{0}(C)\left[1-\alpha\left(T-T_{0}\right)\right]\left[1+\beta\left(P-P_{0}\right)\right]$

where $T_{0}$ and $P_{0}$ are the standard conditions at which the reference density $\rho_{0}(C)$ (which depends on composition) is measured, $\alpha$ is the thermal expansivity and $\beta$ the compressibility.

\section{A.1.2 Energy Equation}

The Energy conservation equation is:

A.4) $\quad \rho \mathrm{c}_{p} \frac{\mathrm{DT}}{\mathrm{Dt}}=-\frac{\partial q_{x}}{\partial x}-\frac{\partial q_{z}}{\partial z}+\mathrm{H}_{r}+\mathrm{H}_{a}+\mathrm{H}_{s}$

A. 5a) $\frac{\partial q_{x}}{\partial x}=-k(\mathrm{~T}, \mathrm{P}, \mathrm{C}) \frac{\partial T}{\partial x}$

|A.6a) $\quad H_{a}=\mathrm{T} \alpha \frac{\mathrm{DP}}{\mathrm{Dt}}$ 
A.6b) $H_{s}=\sigma_{\mathrm{xx}}^{\prime} \dot{\epsilon}_{\mathrm{xx}}+\sigma_{\mathrm{zz}}^{\prime} \dot{\epsilon}_{\mathrm{zz}}+2 \sigma_{\mathrm{xz}}^{\prime} \dot{\epsilon}_{\mathrm{xz}}$

where $c_{p}$ is the heat capacity of the material, DT/Dt is the Lagrangian time derivative of temperature, $\mathrm{q}_{\mathrm{x}}$ and $\mathrm{q}_{\mathrm{z}}$ are the horizontal and vertical components of the heat flux, $\mathrm{k}(\mathrm{T}, \mathrm{P}, \mathrm{C})$ is the thermal conductivity which depends on composition, pressure and temperature, $\mathrm{H}_{\mathrm{a}}$ is the adiabatic heat, $\mathrm{H}_{\mathrm{s}}$ is the viscous shear heating, $\mathrm{H}_{\mathrm{r}}$ is the radioactive heat production which depends only on the composition of the rock considered. Latent heat of melting and crystallization reactions is considered as described below (see Partial Melting for further details). The thermal boundary conditions are: symmetry boundary condition on left and right boundaries (no heat flux), constant temperature on the top boundary and a basal heat flux at the bottom boundary.

\section{A.2 Partial Melting}

Partial melting is handled by using the parametric equations of the dry liquidus and wet solidus reported in Table 1 . The volumetric degree of melt, $\mathbf{M}$, is computed as:

A.7) $\quad$ if $\mathrm{T} \leq \mathrm{T}_{\mathrm{ws}}, \mathrm{M}=0$

$$
\begin{aligned}
& \text { if }_{\mathrm{ws}}<\mathrm{T}<\mathrm{T}_{\mathrm{dl}}, \mathrm{M}=\frac{T-T_{\mathrm{ws}}}{T_{\mathrm{dl}}-T_{\mathrm{ws}}} \\
& \text { if } \mathrm{T} \geq \mathrm{T}_{\mathrm{dl}}, \mathrm{M}=1
\end{aligned}
$$

where $T_{w s}$ and $T_{d l}$ are respectively the temperature of the wet solidus and dry liquidus at a given pressure. The latent heat is taken in account by augmenting the heat capacity ( $\left.\mathrm{Cp}_{\text {eff }}\right)$ and the thermal expansion ( $\left.\alpha_{\text {eff }}\right)$

$$
\text { A.8) } \quad \mathrm{Cp}_{\mathrm{eff}}=\mathrm{Cp}+\mathrm{Q}_{L}\left[\left(\frac{\partial M}{\partial T}\right)_{P}\right]
$$

A.9) $\alpha_{\mathrm{eff}}=\alpha+\mathrm{Q}_{L} \frac{\left[(\partial M / \partial P)_{T}\right]}{T}$

Where $\mathrm{Q}_{\mathrm{L}}$ is the latent heat of melting of the rock.

Density, thermal conductivity, heat capacity, thermal expansivity and compressibility of melt bearing rocks with degree of partial melting $0 \leq M \leq 1$ are computed as:

A.10) $q_{\mathrm{eff}}=\mathrm{q}_{\mathrm{solid}} \cdot(1-M)+q_{\mathrm{molten}} \cdot M$

where $\mathrm{q}_{\text {solid }}$ and $\mathrm{q}_{\text {molten }}$ correspond to the physical property of the solid and melt phases. 


\section{A.3 Rheological Model}

I2VIS accounts for visco-plastic deformation. The dislocation creep viscosity as function of the second invariant of the strain rate tensor $\dot{\varepsilon}_{I I}$ is:

$$
\eta_{\text {disl }}=\frac{1}{2} \eta_{0} \frac{1}{n} \dot{\varepsilon}_{I I}^{\frac{1-n}{n}} \exp \left(\frac{E_{a}+P V_{a}}{n R T}\right)
$$

where $\eta_{0}=\left[\left(A_{D}\right)^{\frac{1}{n}} * 10^{6}\right]^{n}, \mathrm{Ea}, \mathrm{Va}, \mathrm{R}$ and $\mathrm{T}$ are the activation energy, activation volume, gas constant and temperature.

The diffusion creep viscosity is indirectly computed as (Turcotte and Schubert, 2014)) :

A.12) $\eta_{\text {diff }}=\eta_{\text {disl }}\left(\frac{\sigma_{\text {trans }}}{\sigma_{I I}^{\prime}}\right)^{n-1}$

where $\sigma_{\text {trans }}$ and $\sigma_{I I}^{\prime}$ are respectively the stress transition value (which is a constant value that only depends on the rocktype) and the second invariant of the deviatoric stress tensor.

The effective viscosity is calculated as:

A.13) $\eta_{\text {creep }}=\frac{1}{\eta_{\text {disl }}}+\frac{1}{\eta_{\text {diff }}}$

Plasticity is employed with the Drucker-Prager yielding criterion:

A.14) $\sigma_{\text {Yield }}=\operatorname{Cos}\left(\phi_{d r y}\right)+\sin \left(\phi_{d r y}\right) P(1-\lambda)$

where $\mathrm{C}$ is the rock cohesion $(\mathrm{MPa}), \varphi$ is the internal friction angle and $\lambda$ is the pore fluid pressure factor. The maximum viscosity is computed as:

A.15) $\eta_{\text {brit }}=\frac{\sigma_{Y i e l d}}{2 \dot{\varepsilon}_{I I}}$

Thus the effective viscosity is:

A.16)

$\eta_{\text {eff }}=\min \left(\eta_{\text {brit }}, \eta_{\text {creep }}\right)$

Changing the reference dislocation creep viscosity $\eta_{0}$ will thus affect the relative predominance between plastic deformation over viscous deformation.

The presence of melt is taken into account by setting $\lambda=0.4$ and by scaling the creep viscosity with the parametric equation introduced by :

A.17) $\eta_{\mathrm{pm}}=\eta_{\text {creep }} \exp (a \mathrm{M})$ 
where $\eta_{\mathrm{pm}}$ is the modified creep viscosity, $a$ is an empirical parameter $(-28+/-3)$, and $\mathrm{M}$ is the volumetric degree of melt.

In all numerical simulations herein presented we have not tested any plastic strain weakening criterion. Shear localization is given by the rheological contrast between weak and strong rheology, or self develops as consequence of the localized production of shear heating(Burg and Schmalholz, 2008)

\section{A.4 Transport Equation}

Erosion/sedimentation processes are simulated according to the transport equation(Faccenda et al., 2008; Chen et al., 2013). This equation is not conservative, and defines the interface between the air/water layer and underlying rocks. At each timestep, the topography is computed according to:

$$
\text { A.18) } \frac{\partial z}{\partial t}=\mathrm{v}_{z}-v_{x} \frac{\partial z}{\partial x}-v_{s}+\mathrm{v}_{e}
$$

where $\mathrm{z}$ is the elevation of the topography, $\mathrm{v}_{\mathrm{z}}$ and $\mathrm{v}_{\mathrm{x}}$ are the velocity components at the interface, $\mathrm{v}_{\mathrm{s}}$ and $\mathrm{v}_{\mathrm{e}}$ are, respectively, the velocity of erosion and sedimentation. In order to activate erosion or sedimentation processes we set a base level $(19 \mathrm{~km})$, above which the velocity of erosion is nonzero, and below which the velocity of sedimentation is positive. In some experiments the erosion rate is enhanced as a function of the topographic height:

$$
\text { A.19) } V_{e}=2 \mathrm{v}_{e}+\left(H * K_{e}\right)
$$

where $\mathrm{V}_{\mathrm{e}}$ is the standard erosion rate, $\mathrm{H}$ is the topography height measured in $\mathrm{m}$ (which is measured from the water level depth, $20 \mathrm{~km}$ ), and $\mathrm{K}_{\mathrm{e}}$ is the coefficient of erosion rate (measured in $\mathrm{yr}^{-1}$ ). Enhanced erosion is applied after 30 Myrs from the beginning of the numerical experiments (coinciding with the onset of collision) and within an area defined by the minimum topography reached in the pro-foreland basin and the maximum topography recorded in the adjacent orogen. 


\section{Acknowledgments}

This work was supported by Progetto di Ateneo FACCPRAT12 granted by Università degli Studi di Padova to M.F and by Prin 2015 (resp. Prof. Dr. Rodolfo Carosi). We thank Luca Dal Zilio for the stimulating scientific discussions. Zhonghai Li, Lin Chen and the Editor Philippe Agard have greatly improved an earlier version of this manuscript through many useful comments. 


\section{Tables \& Figures}

\begin{tabular}{|c|c|c|c|c|c|}
\hline Parameters & Sediments & Upper Crust & Lower Crust & Oceanic Crust & Mantle \\
\hline Rheology & \multicolumn{2}{|c|}{ 'Wet Quartzite'(a) } & 'Mafic Granulite & 'Plagioclase $A n_{75}{ }^{(a)}$ & 'Dry Olivine $e^{\prime(a)}$ \\
\hline $\boldsymbol{\eta}_{0}\left(\mathrm{~Pa}^{\mathrm{n}} \mathrm{s}\right)$ & \multicolumn{2}{|c|}{$1.97 * 10^{17}$} & $1.13 * 10^{21}$ & $4.80 * 10^{22}$ & $3.98 * 10^{16}$ \\
\hline $\mathrm{n}$ & \multicolumn{2}{|c|}{2.3} & 4.2 & 3.2 & 3.5 \\
\hline $\mathrm{E}_{\mathrm{a}}\left(K J \mathrm{mo} I^{1}\right)$ & \multicolumn{2}{|c|}{154} & 445 & 238 & 532 \\
\hline$V_{a}\left(\mathrm{~cm}^{3} \mathrm{moI}^{1}\right)$ & \multicolumn{2}{|c|}{1} & 1 & 1 & 1 \\
\hline$\sigma_{\text {trans }}(\mathrm{MPa})$ & \multicolumn{2}{|c|}{30} & 0.03 & 30 & 30 \\
\hline $\mathrm{C}(\mathrm{MPa})$ & \multicolumn{2}{|c|}{1} & 1 & 1 & 1 \\
\hline $\sin \Phi$ & \multicolumn{2}{|c|}{0.2} & 0.6 & 0.15 & 0.6 \\
\hline $\mathbf{\rho}\left(k g m^{-3}\right)^{(\mathbf{b})}$ & $2650(2400)^{\text {melted }}$ & $2700(2400)^{\text {melted }}$ & $3000(2900)^{\text {melted }}$ & $3000(2900)^{\text {melted }}$ & 3300 \\
\hline $\boldsymbol{\alpha}\left(K^{1}\right)$ & \multicolumn{2}{|c|}{$3 * 10^{-5}$} & $3^{*} 10^{-5}$ & $3 * 10^{-5}$ & $3 * 10^{-5}$ \\
\hline $\boldsymbol{\beta}\left(P a^{-1}\right)$ & \multicolumn{2}{|c|}{$10^{-11}$} & $10^{-11}$ & $10^{-11}$ & $10^{-11}$ \\
\hline $\boldsymbol{K}^{(\mathrm{c})}\left(W m^{-1} K^{1}\right)$ & \multicolumn{2}{|c|}{$\left[0.64+\frac{807}{\mathrm{~T}+77}\right] \times \exp \left(4 * 10^{-6} * P\right)$} & $\begin{array}{l}\quad\left[1.18+\frac{474}{\mathrm{~T}+77}\right] \times \exp (4 \\
\left.* 10^{-6} \mathrm{P}\right)\end{array}$ & $\begin{array}{l}\quad\left[1.18+\frac{474}{\mathrm{~T}+77}\right] \times \exp (4 \\
\left.* 10^{-6} \mathrm{P}\right)\end{array}$ & $\begin{array}{l}\quad\left[0.73+\frac{1293}{\mathrm{~T}+77}\right] \times \exp (4 \\
\left.* 10^{-6} \mathrm{P}\right)\end{array}$ \\
\hline$c_{p}\left(J K g^{-1} K^{1}\right)$ & $1000(1500)^{\text {melted }}$ & $1000(1500)^{\text {melted }}$ & $1000(1500)^{\text {melted }}$ & $1000(1500)^{\text {melted }}$ & 1000 \\
\hline $\mathbf{H}_{r}^{(\mathbf{b})}\left(\mu W m^{-3}\right)$ & $1.5-5$ & 1.5 & 0.25 & 0.25 & 0.022 \\
\hline
\end{tabular}

Table 1: Reference thermo-mechanical parameters. The $\eta_{0}$ of L.U.C. and U.U.C. is increased in order to obtain a viscosity contrast $(\Omega)$ with respect to the sediments of 1,10 and 100 . Radiogenic heating rates are varied only for sediments. ${ }^{(\mathrm{a})}$ (Ranalli, 1995). ${ }^{\text {(b) }}$ (Turcotte and Schubert, 2014). ${ }^{(\mathrm{c})}$ (Clauser and Huenges, 1995). 


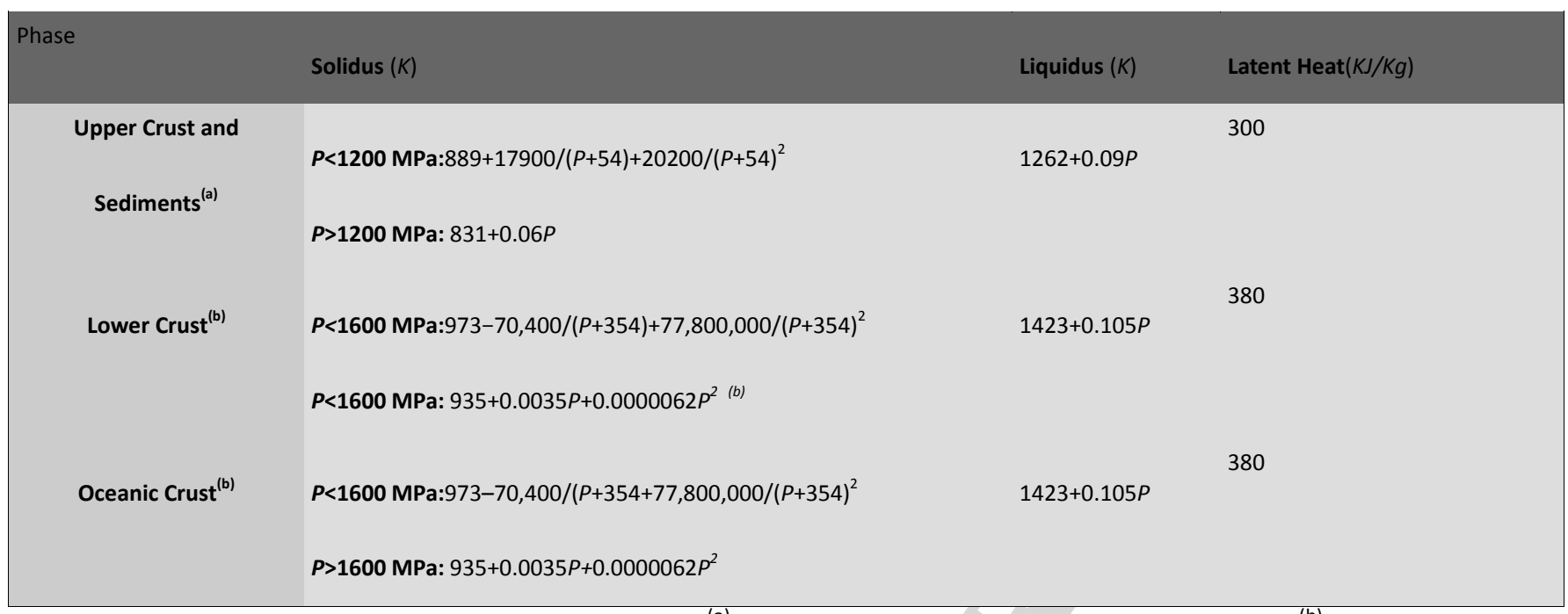

Table 2: Parametrized dry liquidus and wet solidus ${ }^{(a)}$ (Johannes, 1985; Poli and Schmidt, 2002); ${ }^{(b)}$ (Schmidt and Poli, 1998) 


\begin{tabular}{|c|c|c|}
\hline Parameters & Standard & Strong \\
\hline$v_{e}\left(m m y r^{-1}\right)$ & 0.312 & 0.624 \\
\hline $\mathrm{v}_{\mathrm{s}}\left(m m y r^{-1}\right)$ & 0.0312 & 0.0312 \\
\hline$K_{e}\left(y r^{-1}\right)$ & 0 & 0.0006 \\
\hline Timing & // & $30 \mathrm{Ma}$ \\
\hline
\end{tabular}

Table 3: Erosion and sedimentation parameters. The standard set of parameters is active outside the area where focused erosion is applied, and in any other numerical experiment. Strong erosion is applied after 30 Ma the beginning of the simulation between the foreland topographic minimum and the maximum elevation reached. 


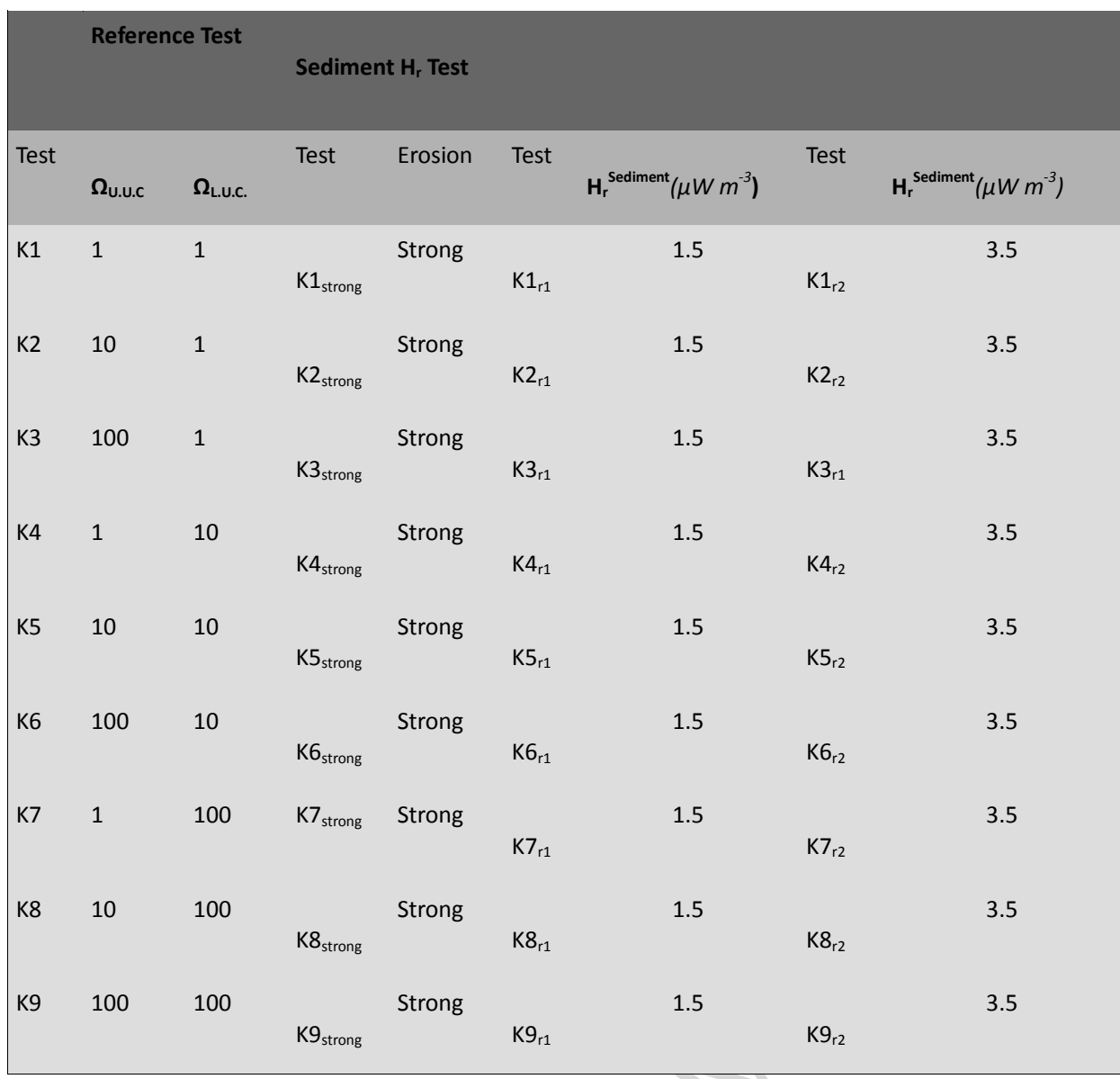

Table 4: Numerical experiments classified according to the $\boldsymbol{\Omega}$ of lower and upper plates. The radiogenic heat production for sediments in reference tests and enhanced erosion tests is listed in Table 1. Erosion rates and radiogenic heat production rates in the reference set of tests are standard. 
Fig1: Initial setup and rocktype legend.

Fig2: $\Omega_{\text {U.U.C }}-\Omega_{\text {L.U.C. }}$ plot for the reference set of experiments: each figure represents a point in the parameter space, and represents the last stage of the simulation $(\sim 58 \mathrm{Ma})$, in the area of interest (800x200 km along the $\mathrm{x}$ and $\mathrm{z}$ directions). Each point is referred in the text as a function of its coordinates in the strength space.

Fig3: Evolution of experiment K1 $\left(\Omega_{\text {U.U.C. }}=1, \Omega_{\text {L.U.C. }} 1\right)$. Each panel represents a snapshot of the numerical simulation at different stages, and it is made up of: P-T-t paths of particles exhumed at the surface (left); composition and isotherms (white number and lines), and position of the selected markers (colored diamonds) (upper right); second invariant of the strain rate field (lower right).

Fig4: Metamorphic surface pattern in experiment K1 $\left(\Omega_{\text {U.U.C. }}=1, \Omega_{\text {L.U.C. }}\right)$. This set of pictures represents the peak metamorphic condition registered by the exhumed markers at different timesteps. $a-b-c)$ Surface exhumation patterns along $x$ and versus Time. a) Maximum temperature $(\mathrm{Tmax}) ; \mathrm{b})$ pressure at $\left.\mathrm{Tmax}\left(\mathrm{P}_{\mathrm{Tmax}}\right) ; \mathrm{c}\right)$ time of achievement of the peak metamorphic conditions $\left(t_{T \max }\right)$. d-e-f-) Representative profiles at different stages of the numerical experiment of (from top to bottom): $\mathrm{x}$ vs $\mathrm{T}_{\max } ; \mathrm{x}$ vs $\mathrm{P}_{\mathrm{Tmax}}$; $\mathrm{x}$ vs $\mathrm{H}$ (topography).

Fig5: Evolution of experiment K7 $\left(\Omega_{\text {U.U.C. }}=1, \Omega_{\text {L.U.C. }} 100\right)$. Figure description same as in Fig. 3.

Fig6: Metamorphic surface pattern in experiment $\mathrm{K} 7\left(\Omega_{\text {U.U.C. }}=1, \Omega_{\text {L.U.C. }} 100\right)$. Figure description same as in Fig. 4

Fig7: Evolution of experiment K6 $\left(\Omega_{\text {U.U.C. }}=100, \Omega_{\text {L.U.C. }}=10\right)$. Figure description same as in Fig. 3.

Fig8: Metamorphic surface pattern in experiment $\mathrm{K} 6\left(\Omega_{\text {U.U.C. }}=100, \Omega_{\text {L.U.C. }}=10\right)$. Figure description same as in Fig. 4

Fig9: Evolution of experiment K9 $\left(\Omega_{\text {U.U.C. }}=100, \Omega_{\text {L.U.C. }}=100\right)$. Figure description same as in Fig. 3.

Fig10: Metamorphic surface pattern in experiment $\mathrm{K} 9\left(\Omega_{\text {U.U.C. }}=100, \Omega_{\text {L.U.C. }} 100\right)$. Figure description same as in Fig. 4 
Fig11: $\Omega_{\text {U.U.C }}-\Omega_{\text {L.U.C. }}$ plot for the set of models $\left(\mathrm{K}_{\text {strong }}\right)$ with enhanced erosion over the foreland flank of the orogeny. Figure description same as in Fig. 2.

Fig12: Evolution of experiment $\mathrm{K} 7_{\text {Strong }}\left(\Omega_{\text {U.U.C. }}=1, \Omega_{\text {L.U.C. }}=100\right)$. Figure description same as in Fig. 3.

Fig13: Metamorphic surface pattern in experiment $\mathrm{K} 7_{\text {Strong }}\left(\Omega_{\text {U.U.C. }}=1, \Omega_{\text {L.U.C. }} 100\right)$. Figure description same as in Fig. 4, except for 4.b in which the two white lines represent the spatial interval in which enhanced erosion is applied.

Fig14: $\Omega_{\text {U.U.C }}-\Omega_{\text {L.U.C. }}$ plot for the set of models $\left(\mathrm{K}_{\mathrm{r} 1}\right)$ with low radiogenic heating rates $\left(\mathrm{H}_{\mathrm{r}}{ }^{\text {Sediments }}\right.$ $=1.5 \mu \mathrm{W} / \mathrm{m}^{3}$ ). Figure description same as in Fig. 2.

Fig.15: $\Omega_{\text {U.U.C }}-\Omega_{\text {L.U.C. }}$ plot for the set of models $\left(\mathrm{K}_{\mathrm{r} 2}\right)$ with medium radiogenic heating rates $\left(\mathrm{H}_{\mathrm{r}}^{\text {Sediments }}=3.5 \mu \mathrm{W} / \mathrm{m}^{3}\right)$. Figure description same as in Fig. 2.

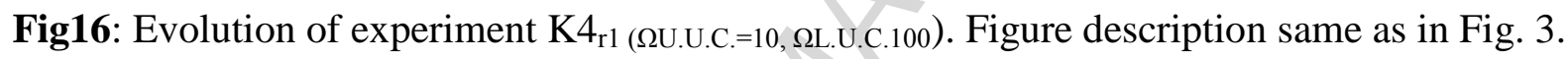

Fig17: Metamorphism in experiment $\mathrm{K} 4_{\mathrm{r} 1}\left(\Omega_{\mathrm{U} \text {.U.C. }}=10, \Omega_{\mathrm{L} . \mathrm{U} . \mathrm{C} .} 100\right)$. Figure description same as in Fig. 4. 


\section{References}

Ader, T. et al. (2012) 'Convergence rate across the Nepal Himalaya and interseismic coupling on the Main Himalayan Thrust: Implications for seismic hazard', Journal of Geophysical Research: Solid Earth, 117(B4), p. n/a-n/a. doi: 10.1029/2011JB009071.

Avouac, J. P. and Burov, E. B. (1996) 'Erosion as a driving mechanism of intracontinental mountain growth', Journal of Geophysical Research: Solid Earth, 101(B8), pp. 17747-17769. doi: 10.1029/96JB01344.

Beaumont, C. et al. (2001) 'Himalayan tectonics explained by extrusion of a low-viscosity crustal channel coupled to focused surface denudation', Nature. Nature Publishing Group, 414(6865), pp. 738-742. doi: 10.1038/414738a.

Beaumont, C. et al. (2004) 'Crustal channel flows: 1. Numerical models with applications to the tectonics of the Himalayan-Tibetan orogen', Journal of Geophysical Research: Solid Earth, 109(B6). doi: 10.1029/2003JB002809.

Beaumont, C. et al. (2006) 'Crustal flow modes in large hot orogens', Geological Society, London, Special Publications. Geological Society of London, 268(1), pp. 91-145. doi:

10.1144/GSL.SP.2006.268.01.05.

Brun, J.-P. and Faccenna, C. (2008) Exhumation of high-pressure rocks driven by slab rollback, Earth and Planetary Science Letters. doi: 10.1016/j.epsl.2008.02.038.

Burg, J.-P. and Gerya T. V. (2005) 'The role of viscous heating in Barrovian metamorphism of collisional orogens: thermomechanical models and application to the Lepontine Dome in the Central Alps', Journal of Metamorphic Geology. Blackwell Science Inc, 23(2), pp. 75-95. doi: 10.1111/j.1525-1314.2005.00563.x.

Burg, J.-P. and Schmalholz, S. M. (2008) 'Viscous heating allows thrusting to overcome crustalscale buckling: Numerical investigation with application to the Himalayan syntaxes', Earth and Planetary Science Letters. Elsevier, 274(1), pp. 189-203. 
Burov, E. and Toussaint, G. (2007) 'Surface processes and tectonics: Forcing of continental subduction and deep processes', Global and Planetary Change, 58(1), pp. 141-164. doi: 10.1016/j.gloplacha.2007.02.009.

Burov, E. et al. (2014) 'Mechanisms of continental subduction and exhumation of HP and UHP rocks', Gondwana Research, 25(2), pp. 464-493. doi: 10.1016/j.gr.2012.09.010.

Capitanio, F. A. et al. (2010) 'India-Asia convergence driven by the subduction of the Greater Indian continent', Nature Geoscience. Nature Publishing Group, 3(2), pp. 136-139. doi: 10.1038/ngeo725.

Carminati, E. et al. (2013) 'Mesozoic Syn- and Postrifting Evolution of the Central Apennines, Italy: The Role of Triassic Evaporites', The Journal of Geology, 121(4), pp. 327-354. doi: 10.1086/670730.

Carosi, R. et al. (2016) 'Middle to late Eocene exhumation of the Greater Himalayan Sequence in the Central Himalayas: Progressive accretion from the Indian plate', Geological Society of America Bulletin. Geological Society of America, 128(11-12), pp. 1571-1592. doi: 10.1130/B31471.1. Chardon, D., Gapais, D. and Cagnard, F. (2009) 'Flow of ultra-hot orogens: a view from the Precambrian, clues for the Phanerozoic', Tectonophysics. Elsevier, 477(3), pp. 105-118. Chemenda, A. I., Burg, J.-P. and Mattauer, M. (2000) 'Evolutionary model of the Himalaya-Tibet system: geopoem: based on new modelling, geological and geophysical data', Earth and Planetary Science Letters, 174(3), pp. 397-409. doi: 10.1016/S0012-821X(99)00277-0.

Chen, L. et al. (2013) 'Numerical modeling of eastern Tibetan-type margin: Influences of surface processes, lithospheric structure and crustal rheology', Gondwana Research, 24(3), pp. 1091-1107. doi: 10.1016/j.gr.2013.01.003.

Chopin, F. et al. (2012) 'Crustal influx, indentation, ductile thinning and gravity redistribution in a continental wedge: Building a Moldanubian mantled gneiss dome with underthrust Saxothuringian material (European Variscan belt)', Tectonics. Wiley Online Library, 31(1). 
Clauser, C. and Huenges, E. (1995) 'Thermal conductivity of rocks and minerals', in. American Geophysical Union, pp. 105-126. doi: 10.1029/RF003p0105.

Collettini, C. and Barchi, M. R. (2004) 'A comparison of structural data and seismic images for low-angle normal faults in the Northern Apennines (Central Italy): constraints on activity', Geological Society, London, Special Publications. Geological Society of London, 224(1), pp. 95112. doi: 10.1144/GSL.SP.2004.224.01.07.

Connolly, J. A. D. (2005) Computation of phase equilibria by linear programming: A tool for geodynamic modeling and its application to subduction zone decarbonation, Earth and Planetary Science Letters. doi: 10.1016/j.eps1.2005.04.033.

Connolly, J. A. D. (2009) 'The geodynamic equation of state: What and how', Geochemistry, Geophysics, Geosystems, 10(10), p. n/a-n/a. doi: 10.1029/2009GC002540.

Copley, A., Avouac, J.-P. and Royer, J.-Y. (2010) 'India-Asia collision and the Cenozoic slowdown of the Indian plate: Implications for the forces driving plate motions', Journal of Geophysical Research, 115(B3), p. B03410. doi: 10.1029/2009JB006634.

Duretz, T., Gerya, T. V. and May, D. A. (2011) 'Numerical modelling of spontaneous slab breakoff and subsequent topographic response', Tectonophysics, 502(1), pp. 244-256. doi: 10.1016/j.tecto.2010.05.024.

Faccenda, M., Gerya, T. V. and Chakraborty, S. (2008) 'Styles of post-subduction collisional orogeny: Influence of convergence velocity, crustal rheology and radiogenic heat production', Lithos, 103(1), pp. 257-287. doi: 10.1016/j.lithos.2007.09.009.

Faccenda, M., Minelli, G. and Gerya, T. V. (2009) Coupled and decoupled regimes of continental collision: Numerical modeling, Earth and Planetary Science Letters. doi: 10.1016/j.epsl.2008.12.021.

Faccenda, M. and Dal Zilio, L. (2017) 'The role of solid--solid phase transitions in mantle convection', Lithos, 268, pp. 198-224. doi: 10.1016/j.lithos.2016.11.007. 
Franěk, J. et al. (2011) 'Model of syn-convergent extrusion of orogenic lower crust in the core of the Variscan belt: implications for exhumation of high-pressure rocks in large hot orogens', Journal of Metamorphic Geology. Blackwell Publishing Ltd, 29(1), pp. 53-78. doi: 10.1111/j.15251314.2010.00903.x.

Gerya, T. V, Perchuk, L. L. and Burg, J.-P. (2008) 'Transient hot channels: perpetrating and regurgitating ultrahigh-pressure, high-temperature crust-mantle associations in collision belts', Lithos. Elsevier, 103(1), pp. 236-256.

Gerya, T. V. and Yuen, D. A. (2003) 'Characteristics-based marker-in-cell method with conservative finite-differences schemes for modeling geological flows with strongly variable transport properties', Physics of the Earth and Planetary Interiors, 140(4), pp. 293-318. doi: 10.1016/j.pepi.2003.09.006.

Gerya, T. V. and Meilick, F. I. (2011) 'Geodynamic regimes of subduction under an active margin: effects of rheological weakening by fluids and melts', Journal of Metamorphic Geology. Blackwell Publishing Ltd, 29(1), pp. 7-31. doi: 10.1111/j.1525-1314.2010.00904.x.

Grujic, D. et al. (1996) 'Ductile extrusion of the Higher Himalayan Crystalline in Bhutan: evidence from quartz microfabrics', Tectonophysics, 260(1), pp. 21-43. doi: 10.1016/0040-1951(96)00074-1. Guillot, S. et al. (2003) 'Reconstructing the total shortening history of the NW Himalaya', Geochemistry, Geophysics, Geosystems, 4(7). doi: 10.1029/2002GC000484.

van Hinsbergen, D. J. J. et al. (2011) 'Restoration of Cenozoic deformation in Asia and the size of Greater India', Tectonics, 30(5), p. n/a-n/a. doi: 10.1029/2011TC002908.

Hodges, K. V. (2000) 'Tectonics of the Himalaya and southern Tibet from two perspectives', GSA Bulletin, 112(3).

Iaccarino, S. et al. (2015) 'Pressure-temperature-time-deformation path of kyanite-bearing migmatitic paragneiss in the Kali Gandaki valley (Central Nepal): Investigation of Late EoceneEarly Oligocene melting processes', Lithos, 231, pp. 103-121. doi: 10.1016/j.lithos.2015.06.005. 
Iaccarino, S. et al. (2016) 'Geology and tectono-metamorphic evolution of the Himalayan metamorphic core: insights from the Mugu Karnali transect, Western Nepal (Central Himalaya)', Journal of Metamorphic Geology. doi: 10.1111/jmg.12233.

Imayama, T. et al. (2012) 'Two-stage partial melting and contrasting cooling history within the Higher Himalayan Crystalline Sequence in the far-eastern Nepal Himalaya', Lithos, 134, pp. 1-22. doi: 10.1016/j.lithos.2011.12.004.

Jagoutz, O. et al. (2015) 'Anomalously fast convergence of India and Eurasia caused by double subduction', Nature Geoscience. Nature Research, 8(6), pp. 475-478. doi: 10.1038/ngeo2418. Jamieson, R. A. et al. (2004) 'Crustal channel flows: 2. Numerical models with implications for metamorphism in the Himalayan-Tibetan orogen', Journal of Geophysical Research: Solid Earth, 109(B6). doi: 10.1029/2003JB002811.

Johannes, W. (1985) 'The significance of experimental studies for the formation of migmatites', in Migmatites. Boston, MA: Springer US, pp. 36-85. doi: 10.1007/978-1-4613-2347-1_2.

Jolivet, L. et al. (1998) 'Midcrustal shear zones in postorogenic extension: Example from the northern Tyrrhenian Sea', Journal of Geophysical Research: Solid Earth, 103(B6), pp. 1212312160. doi: 10.1029/97JB03616.

Kohn, M. J. (2008) 'P-T-t data from central Nepal support critical taper and repudiate large-scale channel flow of the Greater Himalayan Sequence', Geological Society of America Bulletin. Geological Society of America, 120(3-4), pp. 259-273. doi: 10.1130/B26252.1.

Kroner, U. and Romer, R. L. (2013) 'Two plates_many subduction zones: the Variscan orogeny reconsidered', Gondwana Research. Elsevier, 24(1), pp. 298-329.

Li, Z., Liu, M. and Gerya, T. (2016) 'Lithosphere delamination in continental collisional orogens: A systematic numerical study', Journal of Geophysical Research: Solid Earth. Wiley Online Library, 121(7), pp. 5186-5211.

Li, Z. H., Gerya, T. V and BURG, J. (2010) 'Influence of tectonic overpressure on P-T paths of 
HP-UHP rocks in continental collision zones: thermomechanical modelling', Journal of Metamorphic Geology. Wiley Online Library, 28(3), pp. 227-247.

Liao, J. and Gerya, T. (2017) 'Partitioning of crustal shortening during continental collision: 2-D thermomechanical modeling', Journal of Geophysical Research: Solid Earth. John Wiley \& Sons, Ltd. doi: 10.1002/2016JB013398.

Macfarlane, A. M. (1992) 'The tectonic evolution of the core of the Himalaya, Langtang National Park, central Nepal'. Massachusetts Institute of Technology.

Montomoli, C., Carosi, R. and Iaccarino, S. (2015) 'Tectonometamorphic discontinuities in the Greater Himalayan Sequence: a local or a regional feature?', Geological Society, London, Special Publications. Geological Society of London, 412(1), pp. 25-41. doi: 10.1144/SP412.3.

Nelson et al. (1996) 'Partially Molten Middle Crust Beneath Southern Tibet: Synthesis of Project INDEPTH Results', Science (New York, N.Y.), 274(5293), pp. 1684-8. Available at: http://www.ncbi.nlm.nih.gov/pubmed/8939851 (Accessed: 27 January 2017).

Pauselli, C. et al. (2006) 'The crustal structure of the northern apennines (Central Italy): An insight by the crop03 seismic line', American Journal of Science. American Journal of Science, 306(6), pp. 428-450. doi: 10.2475/06.2006.02.

Platt, J. P. (1986) 'Dynamics of orogenic wedges and the uplift of high-pressure metamorphic rocks', Geological society of America bulletin. Geological Society of America, 97(9), pp. 10371053.

Platt, J. P. (1993) 'Exhumation of high- pressure rocks: A review of concepts and processes', Terra nova. Wiley Online Library, 5(2), pp. 119-133.

Poli, S. and Schmidt, M. W. (2002) 'Petrology of Subducted Slabs', Annual Review of Earth and Planetary Sciences. Annual Reviews 4139 El Camino Way, P.O. Box 10139, Palo Alto, CA 943030139, USA , 30(1), pp. 207-235. doi: 10.1146/annurev.earth.30.091201.140550.

Pusok, A. E. and Kaus, B. J. P. (2015) 'Development of topography in 3- D continental- collision 
models', Geochemistry, Geophysics, Geosystems. Wiley Online Library, 16(5), pp. 1378-1400.

Ranalli, G. (1995) Rheology of the earth. Chapman \& Hall.

Reuber, G. et al. (2016) 'Nonlithostatic pressure during subduction and collision and the formation of (ultra)high-pressure rocks', Geology.

Rosenberg, C. L. and Kissling, E. (2013) 'Three-dimensional insight into Central-Alpine collision: Lower-plate or upper-plate indentation?', Geology. Geological Society of America, 41(12), pp. 1219-1222. doi: 10.1130/G34584.1.

Rosenberg, C. L. et al. (no date) 'Relating orogen width to shortening, erosion, and exhumation during Alpine collision'. doi: 10.1002/2014TC003736>.

Scaillet, B., France-Lanord, C. and Le Fort, P. (1990) 'Badrinath-Gangotri plutons (Garhwal, India): petrological and geochemical evidence for fractionation processes in a high Himalayan leucogranite', Journal of Volcanology and Geothermal Research, 44(1-2), pp. 163-188. doi: 10.1016/0377-0273(90)90017-A.

Schmidt, M. W. and Poli, S. (1998) 'Experimentally based water budgets for dehydrating slabs and consequences for arc magma generation', Earth and Planetary Science Letters, 163(163), pp. 361379.

Schulmann, K. et al. (2008) 'Vertical extrusion and horizontal channel flow of orogenic lower crust: key exhumation mechanisms in large hot orogens?', Journal of Metamorphic Geology. Wiley Online Library, 26(2), pp. 273-297.

Schulmann, K. et al. (2009) 'An Andean type Palaeozoic convergence in the Bohemian Massif', Comptes Rendus Geoscience, 341(2-3), pp. 266-286. doi: 10.1016/j.crte.2008.12.006.

Schulmann, K. et al. (2014) 'Anatomy of a diffuse cryptic suture zone: An example from the Bohemian Massif, European Variscides', Geology , 42(4), pp. 275-278. doi: 10.1130/G35290.1. Sizova, E. et al. (2010) 'Subduction styles in the Precambrian: Insight from numerical experiments', Lithos, 116(3-4), pp. 209-229. doi: 10.1016/j.lithos.2009.05.028. 
Sizova, E., Gerya, T. and Brown, M. (2012) 'Exhumation mechanisms of melt-bearing ultrahigh pressure crustal rocks during collision of spontaneously moving plates', Journal of Metamorphic Geology. Blackwell Publishing Ltd, 30(9), pp. 927-955. doi: 10.1111/j.1525-1314.2012.01004.x. Sizova, E., Gerya, T. and Brown, M. (2014) 'Contrasting styles of Phanerozoic and Precambrian continental collision', Gondwana Research. International Association for Gondwana Research, 25(2), pp. 522-545. doi: 10.1016/j.gr.2012.12.011.

Sizova, E. et al. (2015) 'Generation of felsic crust in the Archean: A geodynamic modeling perspective', Precambrian Research. Elsevier B.V., 271, pp. 198-224. doi:

10.1016/j.precamres.2015.10.005.

Speranza, F. and Chiappini, M. (2002) 'Thick-skinned tectonics in the external Apennines, Italy: New evidence from magnetic anomaly analysis', Journal of Geophysical Research: Solid Earth, 107(B11), p. ETG 8-1-ETG 8-19. doi: 10.1029/2000JB000027.

Toussaint, G., Burov, E. and Jolivet, L. (2004) 'Continental plate collision: Unstable vs. stable slab dynamics', Geology. Geological Society of America, 32(1), p. 33. doi: 10.1130/G19883.1.

Toussaint, G., Burov, E. and Avouac, J.-P. (2004) 'Tectonic evolution of a continental collision zone: A thermomechanical numerical model', Tectonics, 23(6), p. n/a-n/a. doi: 10.1029/2003TC001604. Turcotte, D. L. and Schubert, G. (2014) 'Geodynamics'. Cambridge University Press.

Vanderhaeghe, O. and Teyssier, C. (2001) 'Partial melting and flow of orogens', Tectonophysics. Elsevier, 342(3), pp. 451-472.

Vanderhaeghe, O. (2009) 'Migmatites, granites and orogeny: Flow modes of partially-molten rocks and magmas associated with melt/solid segregation in orogenic belts', Tectonophysics. Elsevier, 477(3), pp. 119-134.

Vanderhaeghe, O. (2012) 'The thermal-mechanical evolution of crustal orogenic belts at convergent plate boundaries: A reappraisal of the orogenic cycle', Journal of Geodynamics. Elsevier, 56, pp. $124-145$. 
Vidal, P., Cocherie, A. and Le Fort, P. (1982) 'Geochemical investigations of the origin of the Manaslu leucogranite (Himalaya, Nepal)', Geochimica et Cosmochimica Acta, 46(11), pp. 22792292. doi: 10.1016/0016-7037(82)90201-0.

Vignaroli, G. et al. (2009) 'Insights from the Apennines metamorphic complexes and their bearing on the kinematics evolution of the orogen', Geological Society, London, Special Publications. Geological Society of London, 311(1), pp. 235-256. doi: 10.1144/SP311.9. Vogt, K., Gerya, T. V. and Castro, A. (2012) 'Crustal growth at active continental margins: Numerical modeling', Physics of the Earth and Planetary Interiors, 192-193, pp. 1-20. doi: 10.1016/j.pepi.2011.12.003.

Wang, J.-M., Rubatto, D. and Zhang, J.-J. (2015) 'Timing of Partial Melting and Cooling across the Greater Himalayan Crystalline Complex (Nyalam, Central Himalaya): In-sequence Thrusting and its Implications', Journal of Petrology, 56(9), pp. 1677-1702. Available at: http://dx.doi.org/10.1093/petrology/egv050.

Warren, C. J., Beaumont, C. and Jamieson, R. A. (2008) Modelling tectonic styles and ultra-high pressure (UHP) rock exhumation during the transition from oceanic subduction to continental collision, Earth and Planetary Science Letters. doi: 10.1016/j.eps1.2007.11.025.

Yin, A. and Harrison, T. M. (2000) 'Geologic Evolution of the Himalayan-Tibetan Orogen', Annual Review of Earth and Planetary Sciences. Annual Reviews 4139 El Camino Way, P.O. Box 10139, Palo Alto, CA 94303-0139, USA , 28(1), pp. 211-280. doi: 10.1146/annurev.earth.28.1.211.

Yin, A. (2006) 'Cenozoic tectonic evolution of the Himalayan orogen as constrained by along-strike variation of structural geometry, exhumation history, and foreland sedimentation', Earth-Science Reviews, 76(1), pp. 1-131. doi: 10.1016/j.earscirev.2005.05.004. 
Figure 1

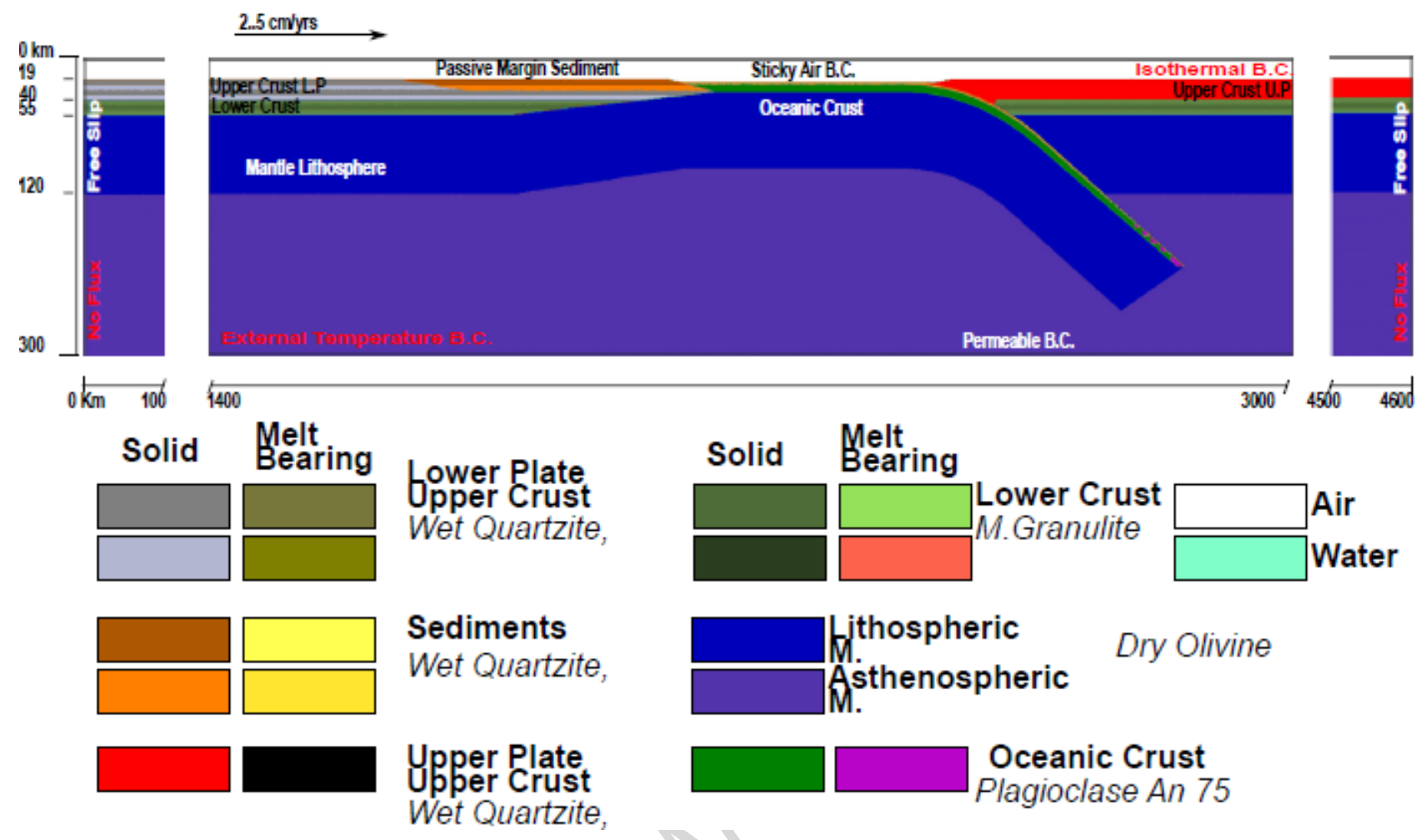




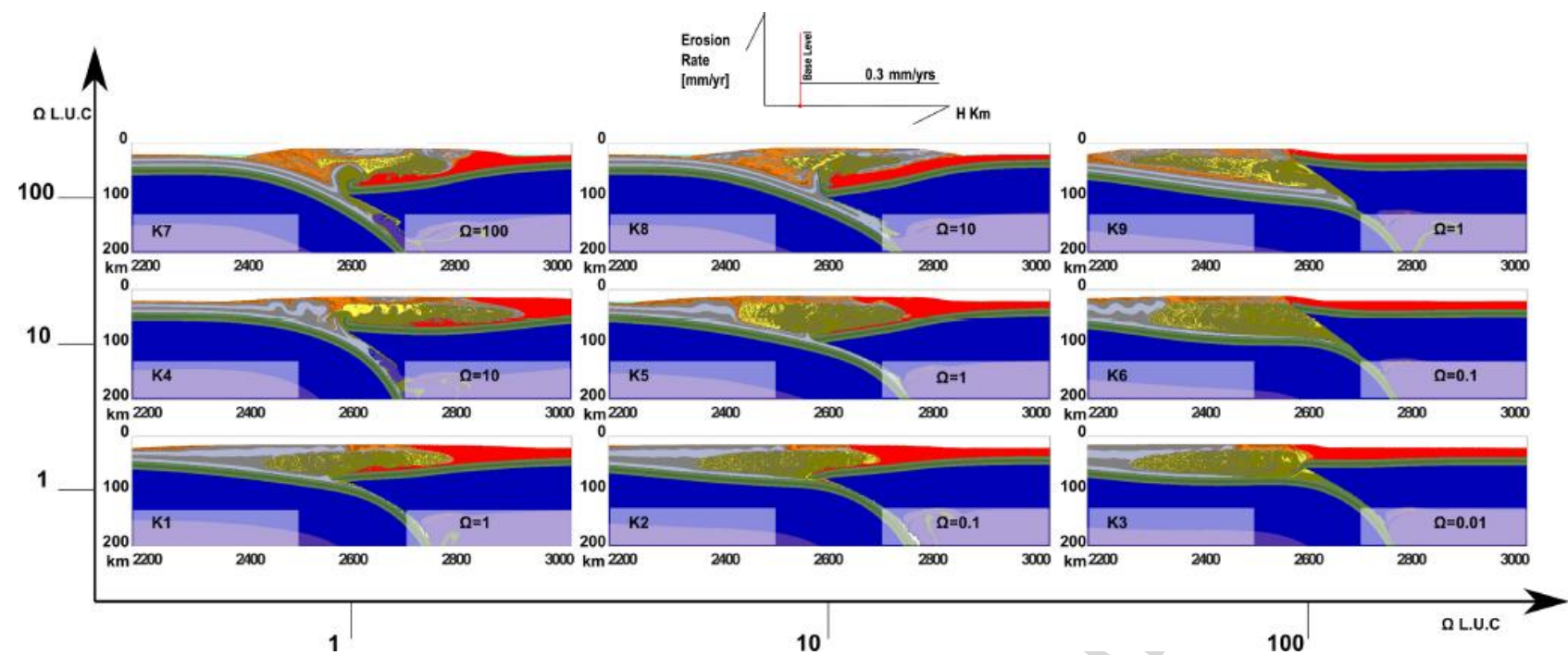

Figure 2 


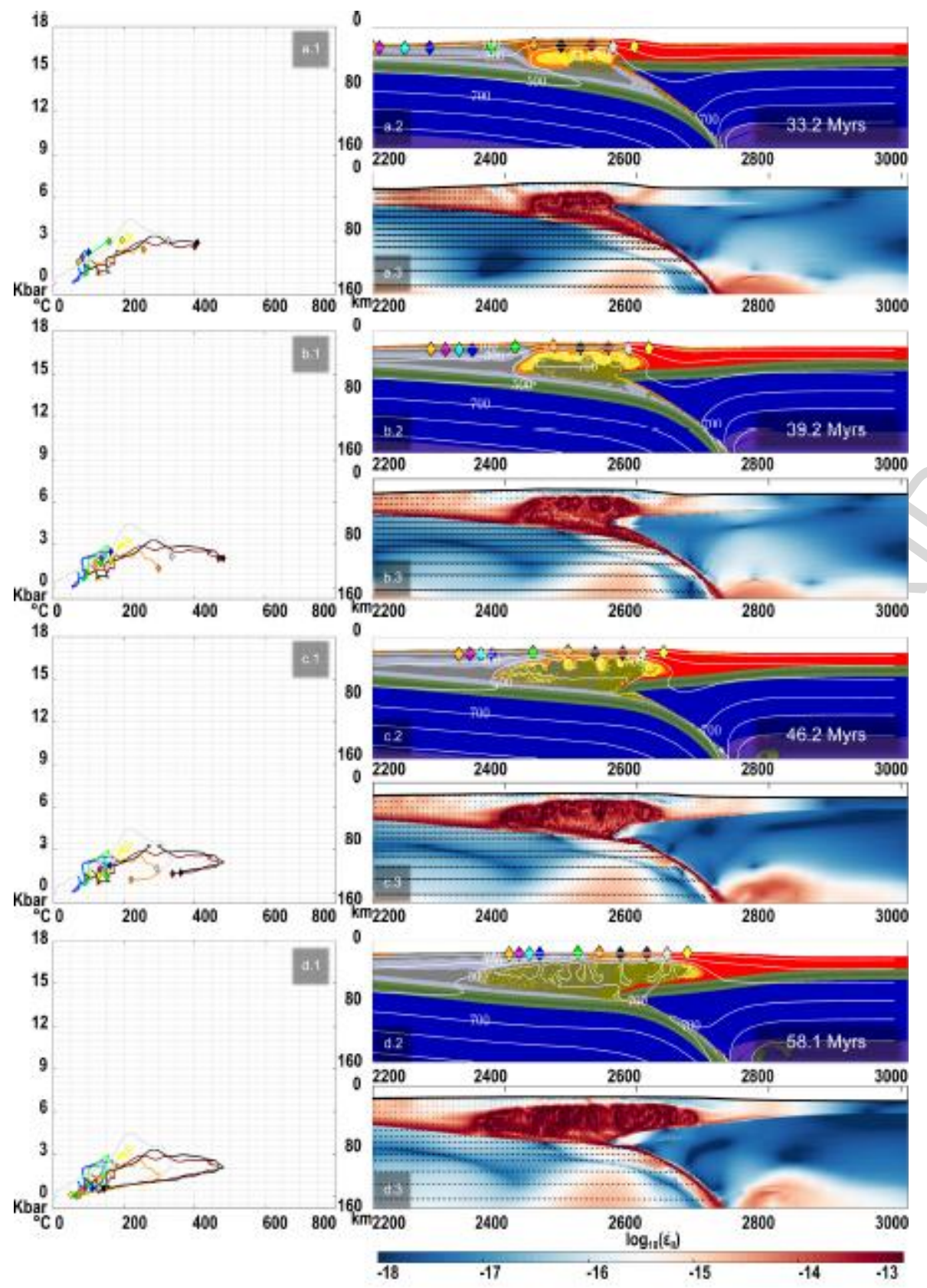

Figure 3 

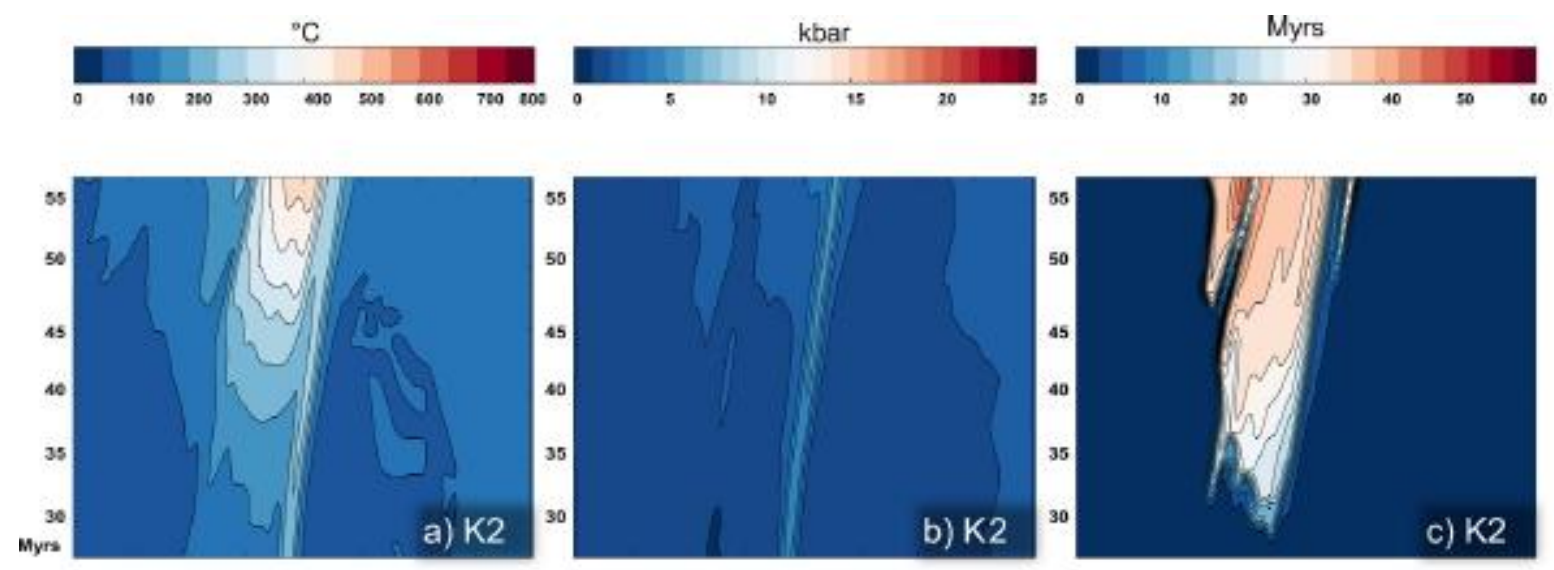

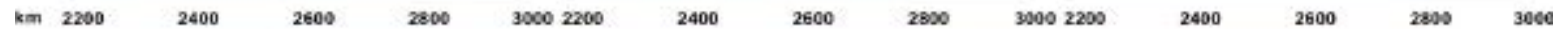
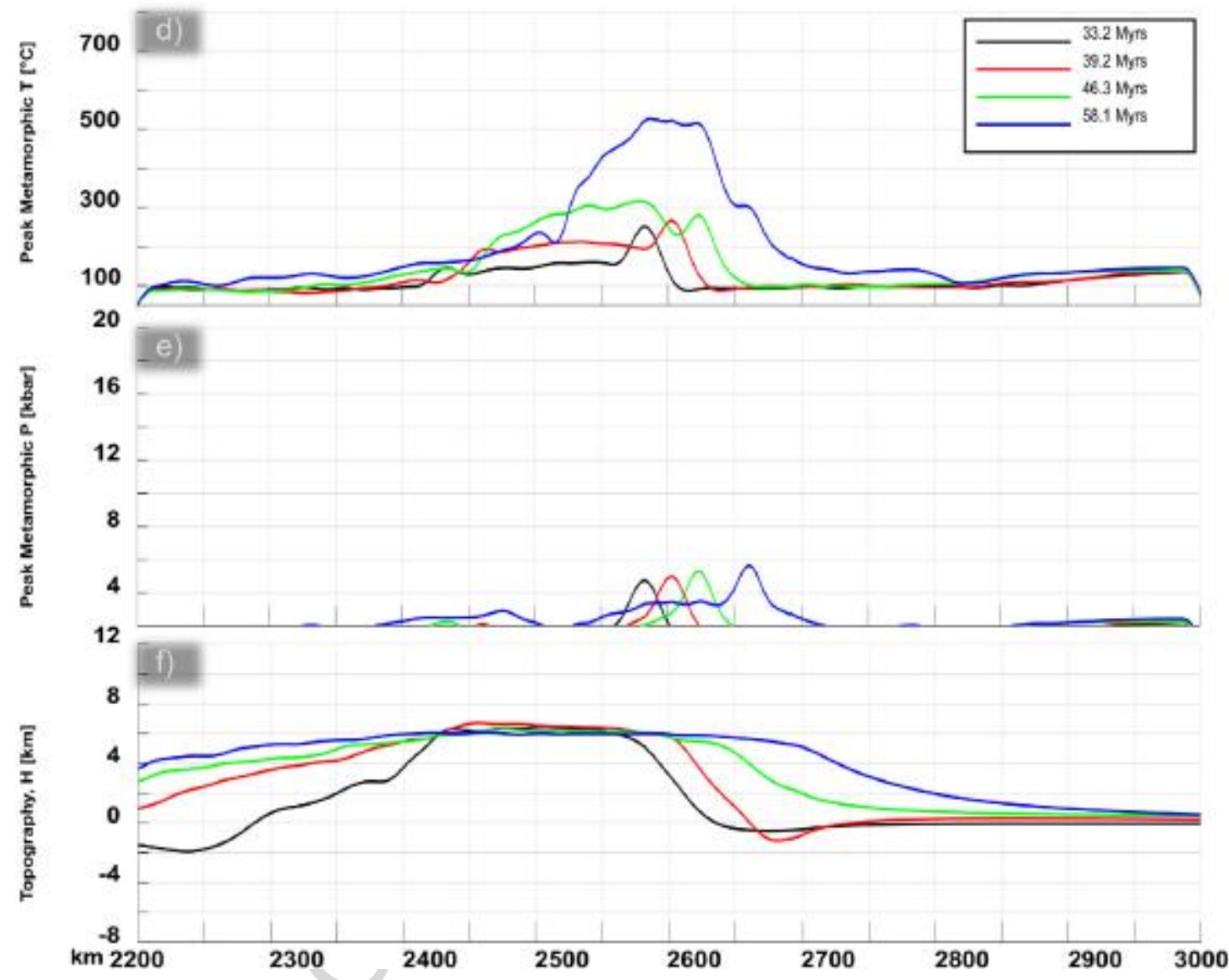

Figure 4 


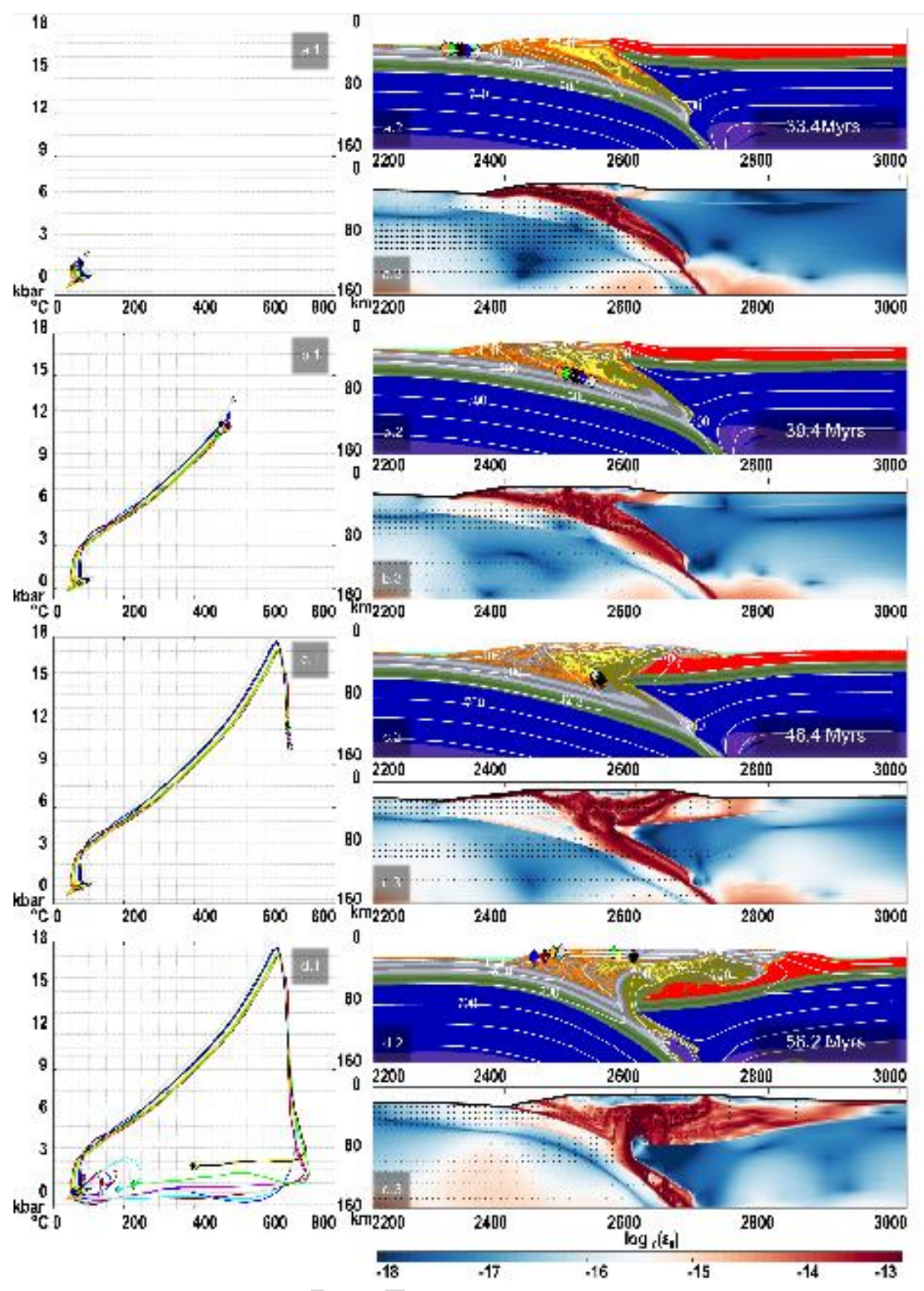

Figure 5 

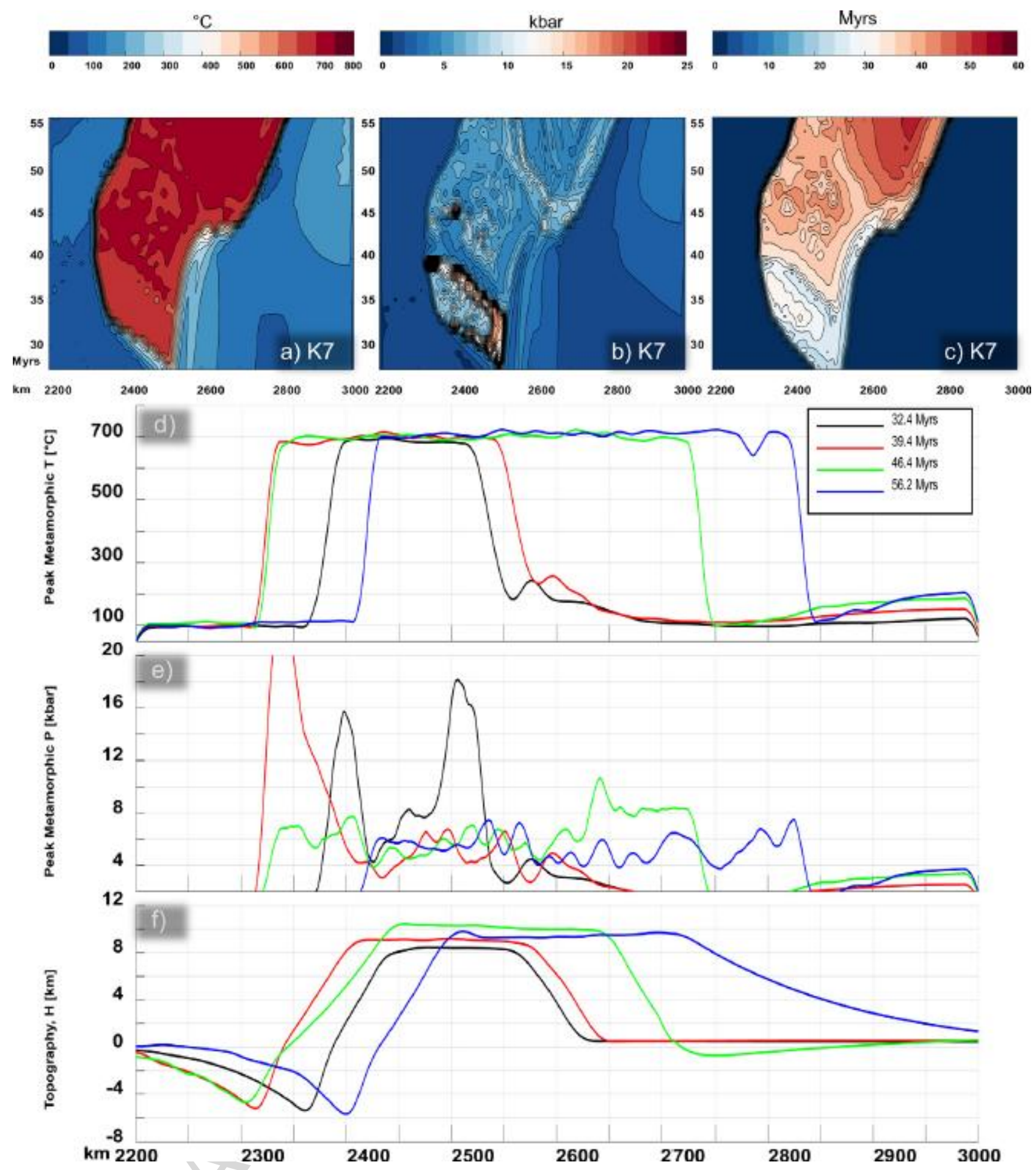

Figure 6 


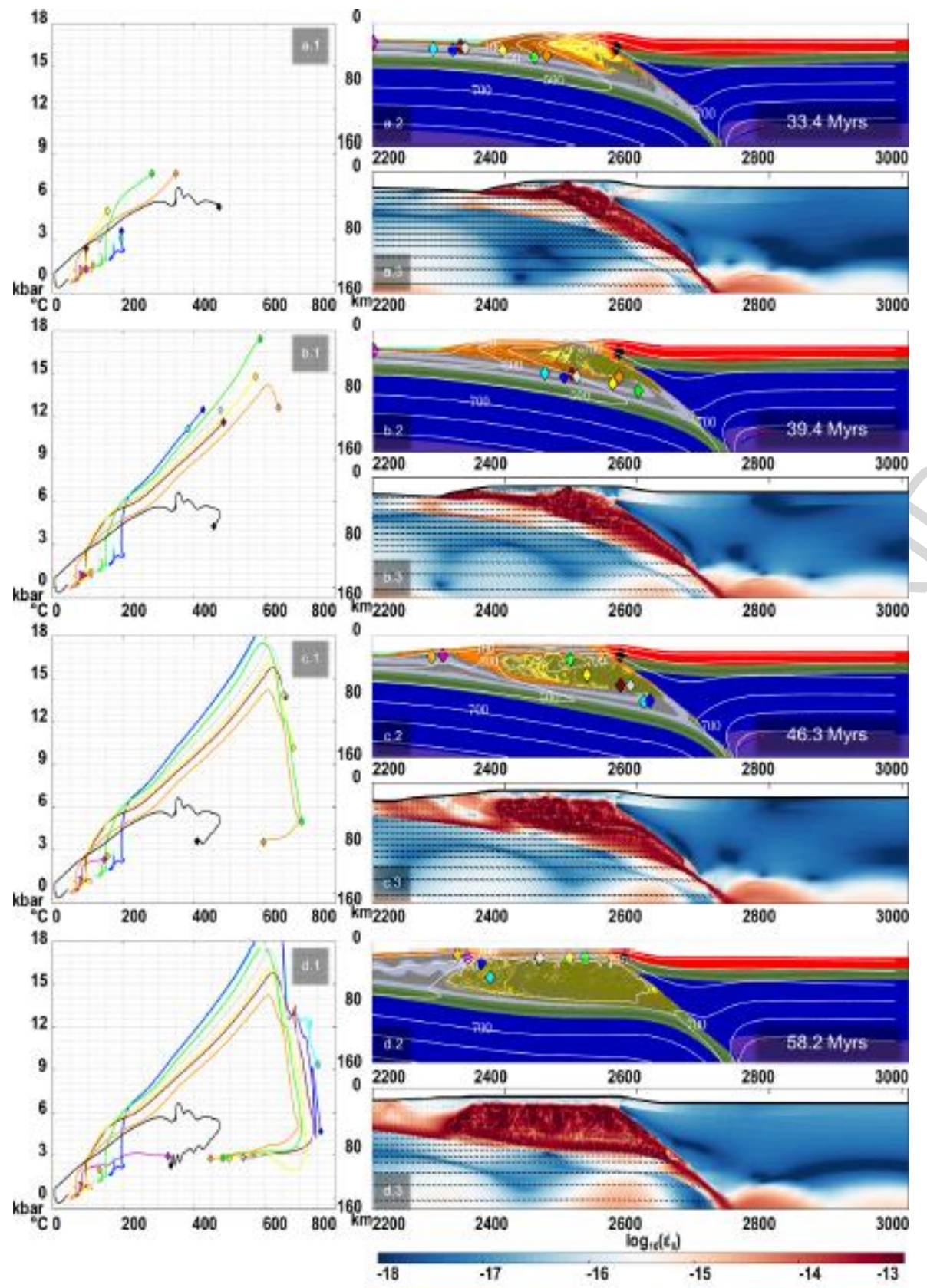

Figure 7 

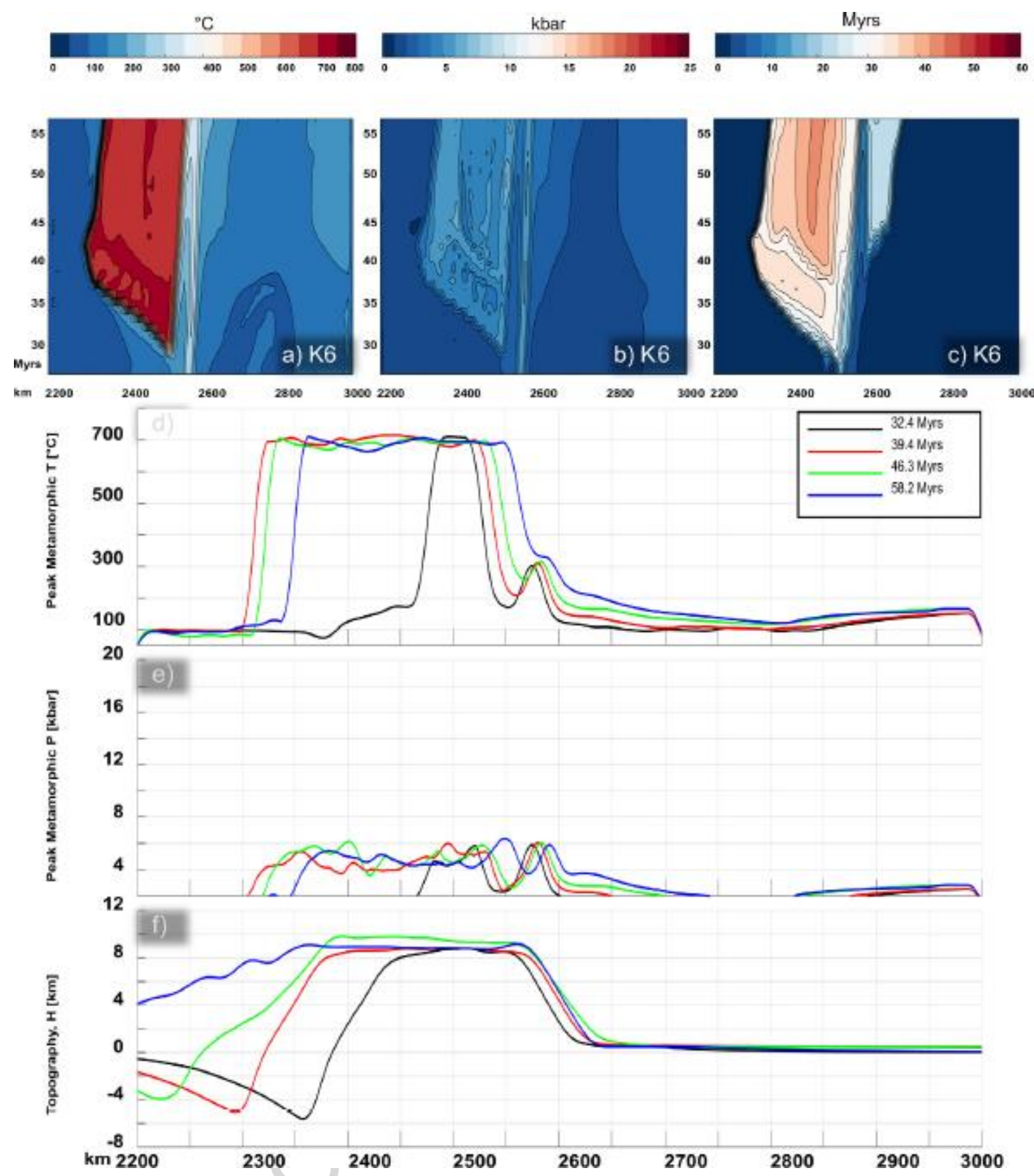

Figure 8 


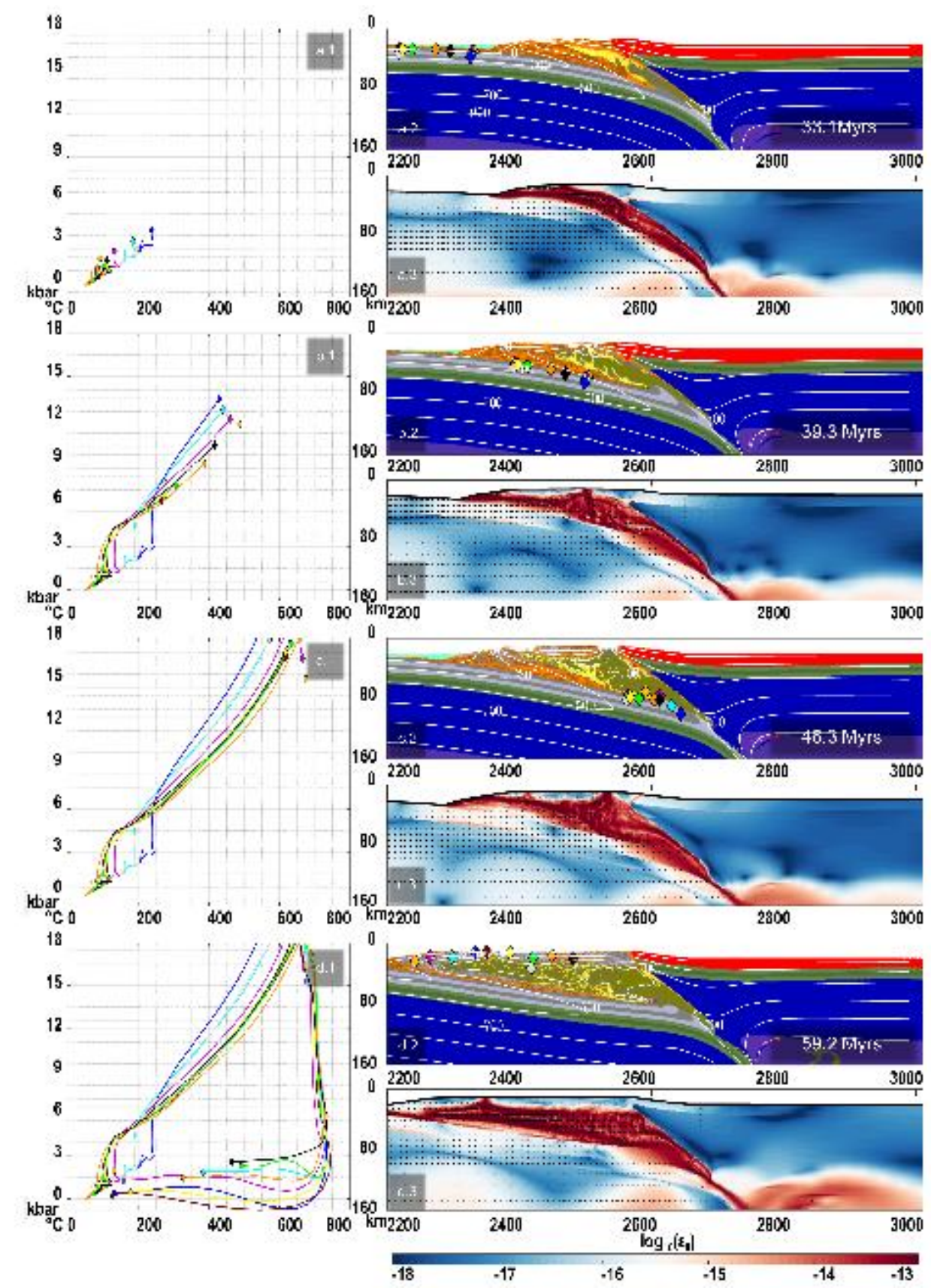

Figure 9 

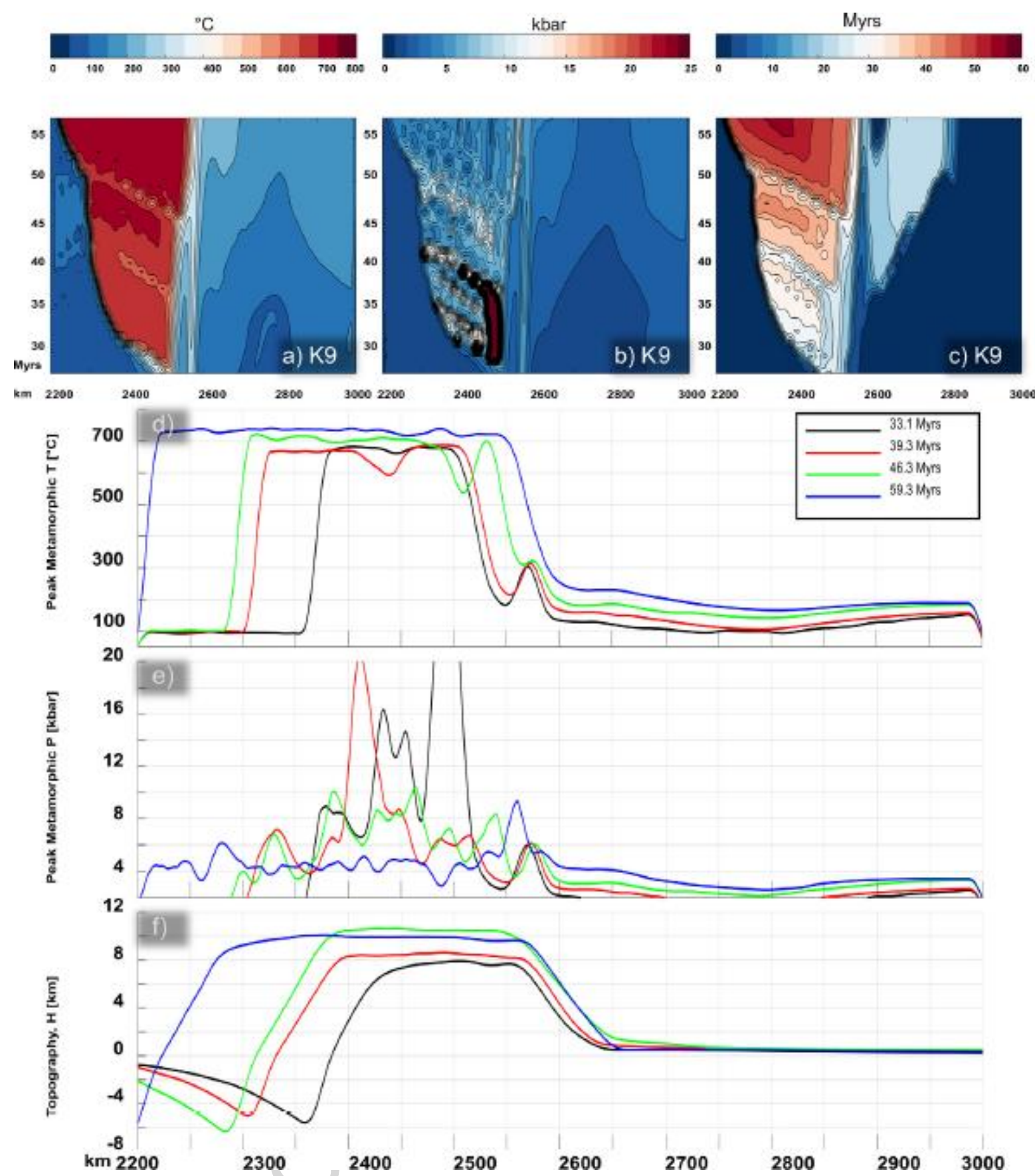

Figure 10 


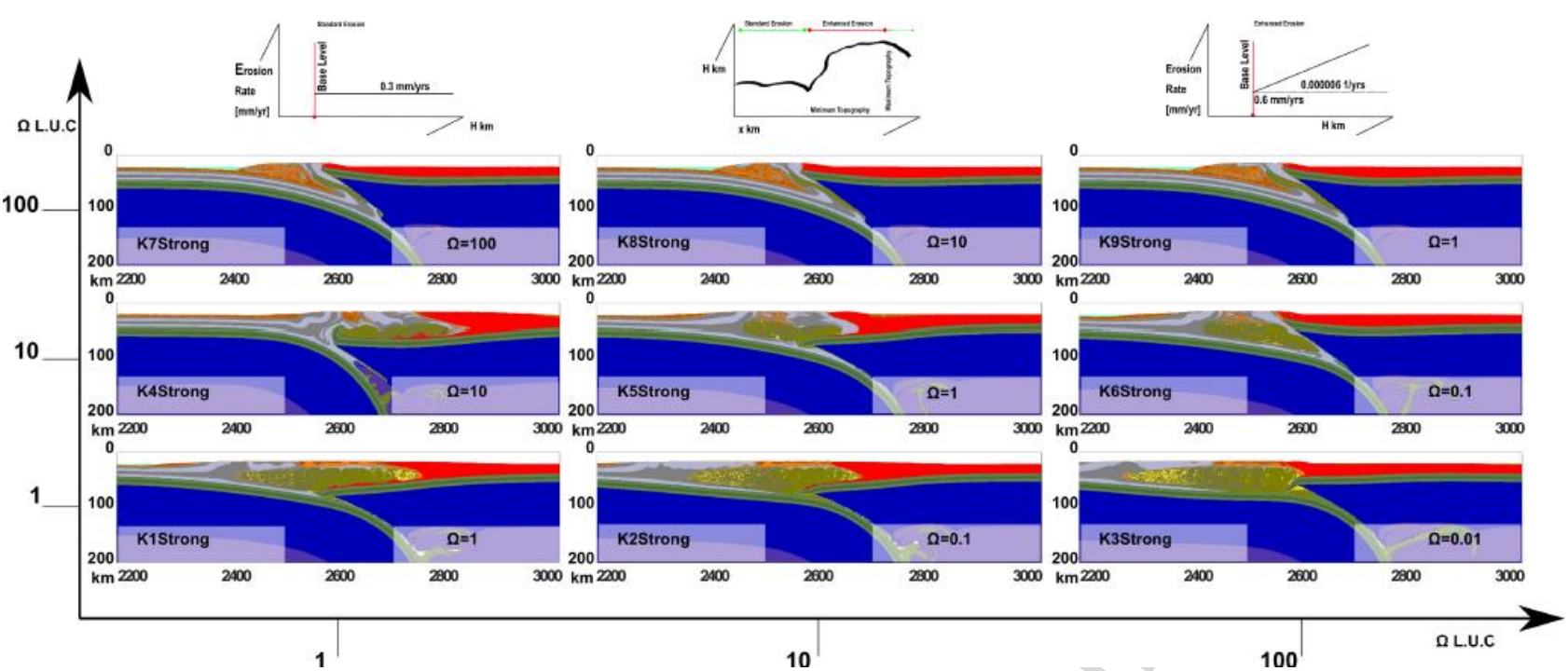

Figure 11 


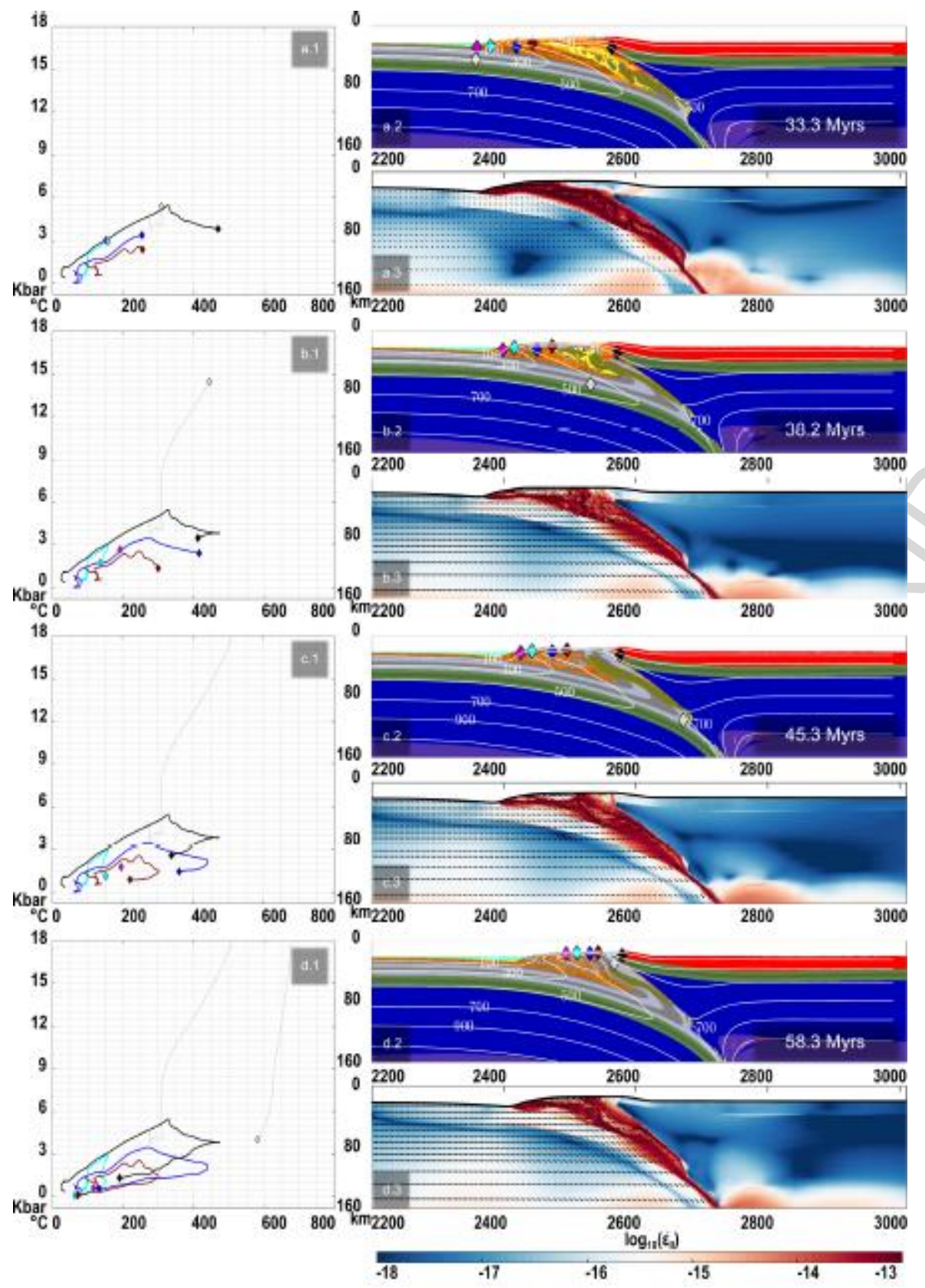

Figure 12 

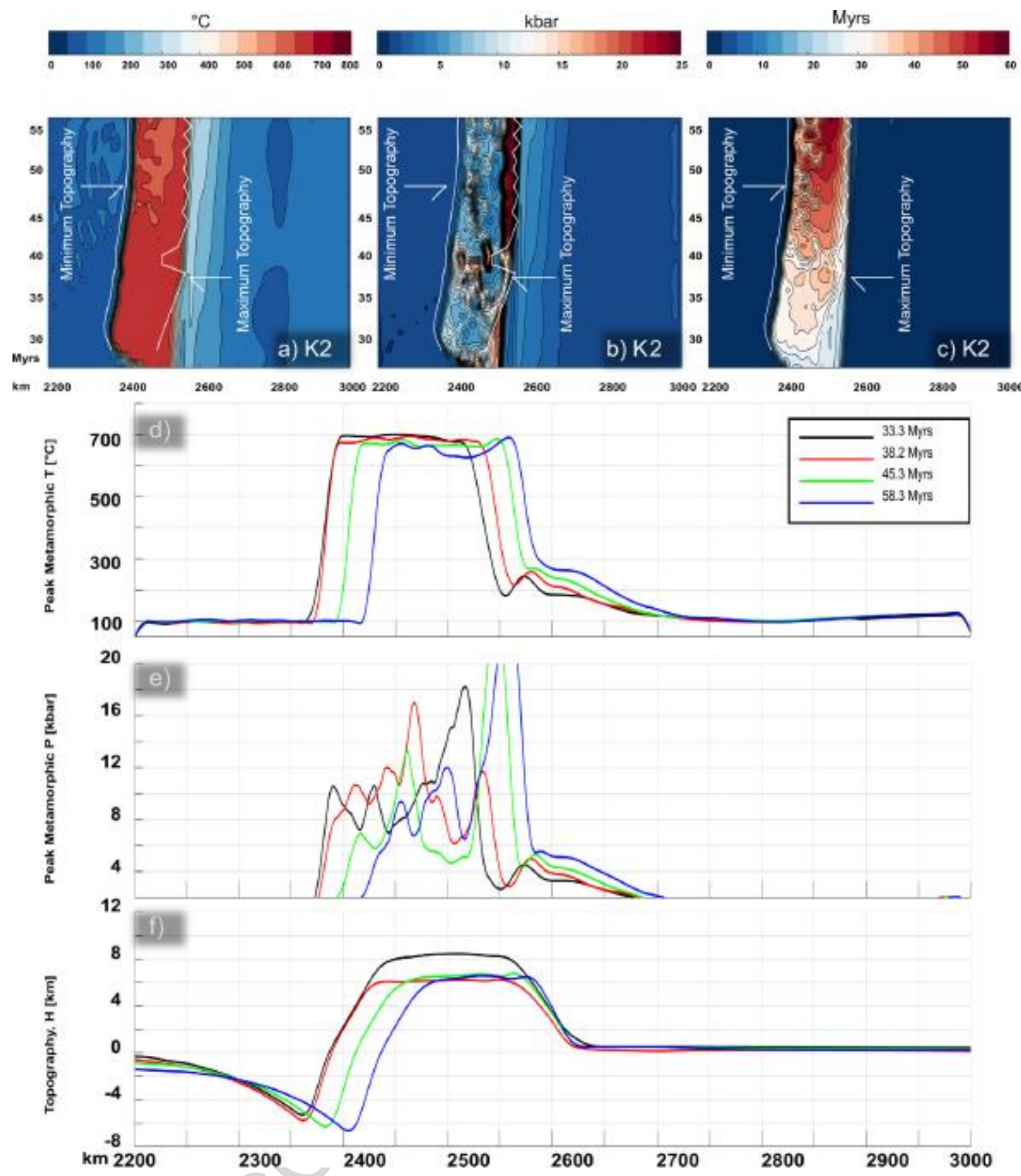

Figure 13 


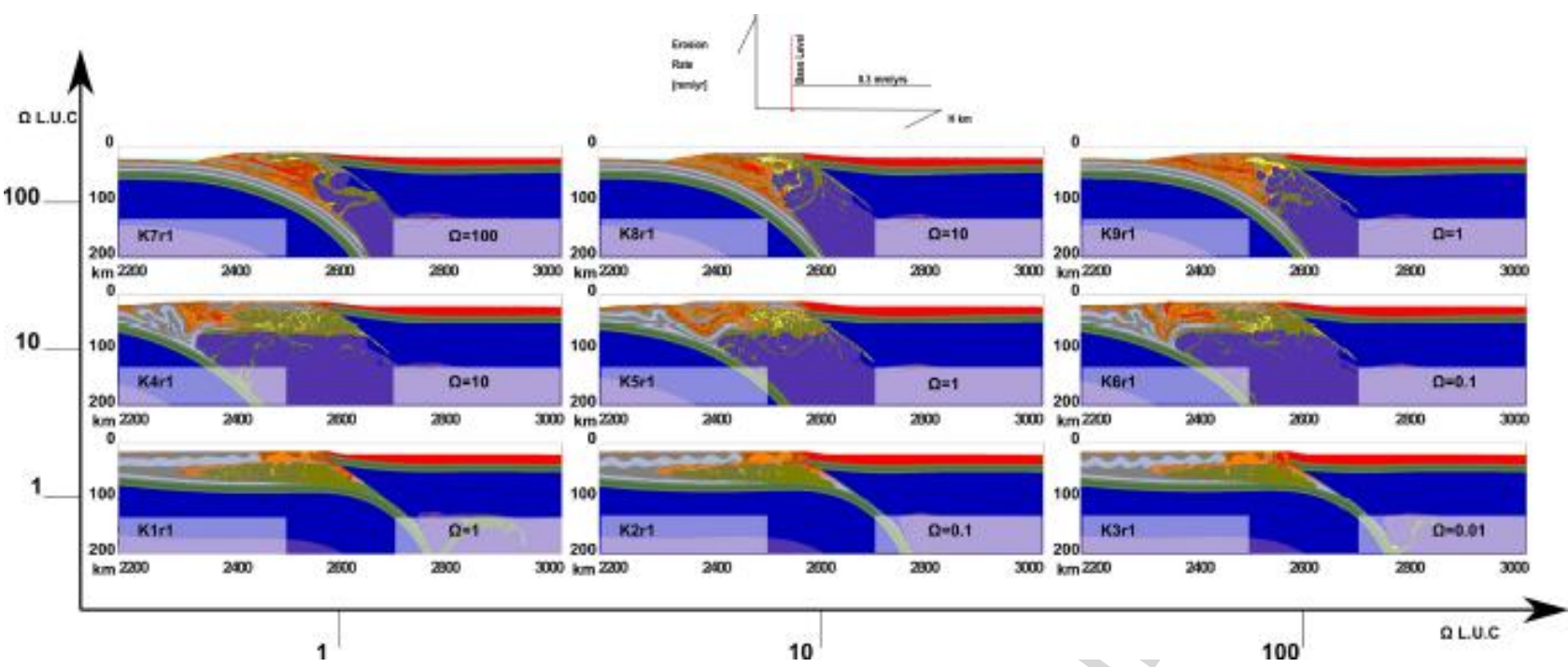

Figure 14 


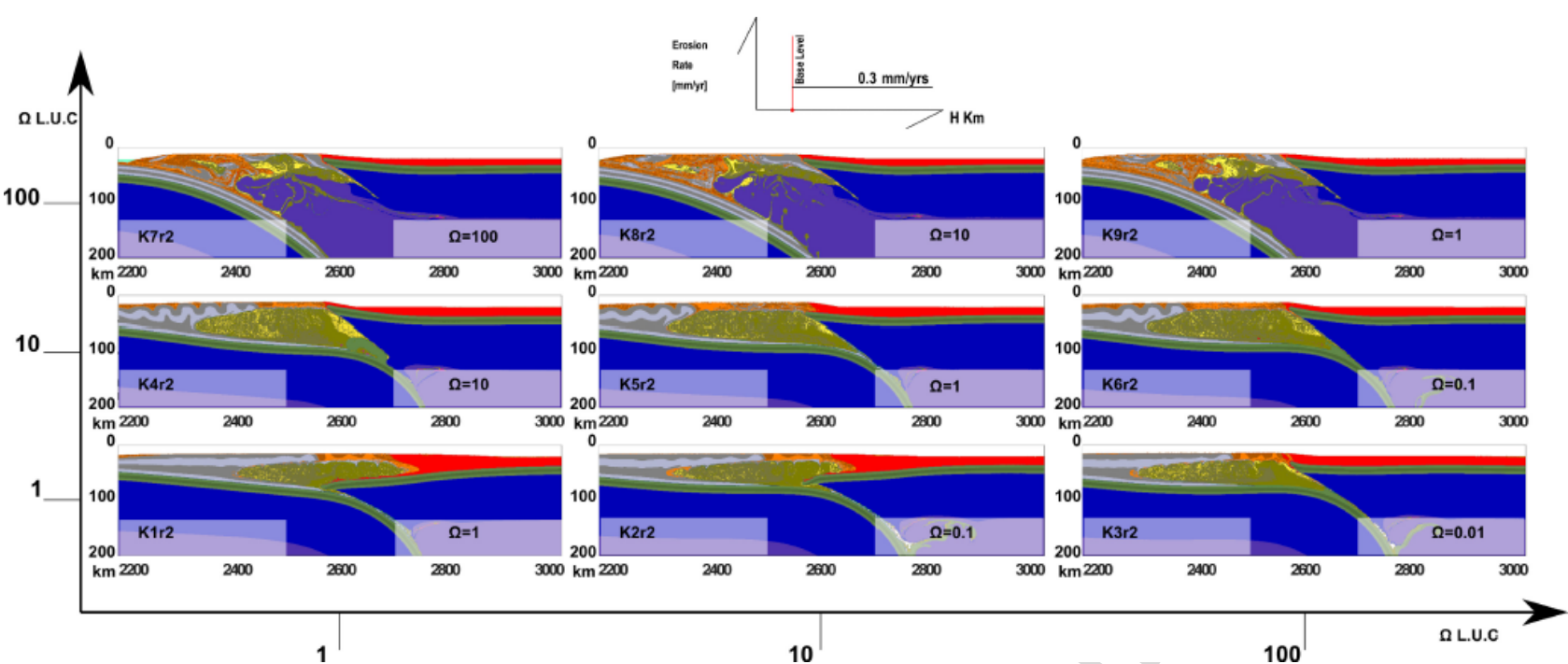

Figure 15 


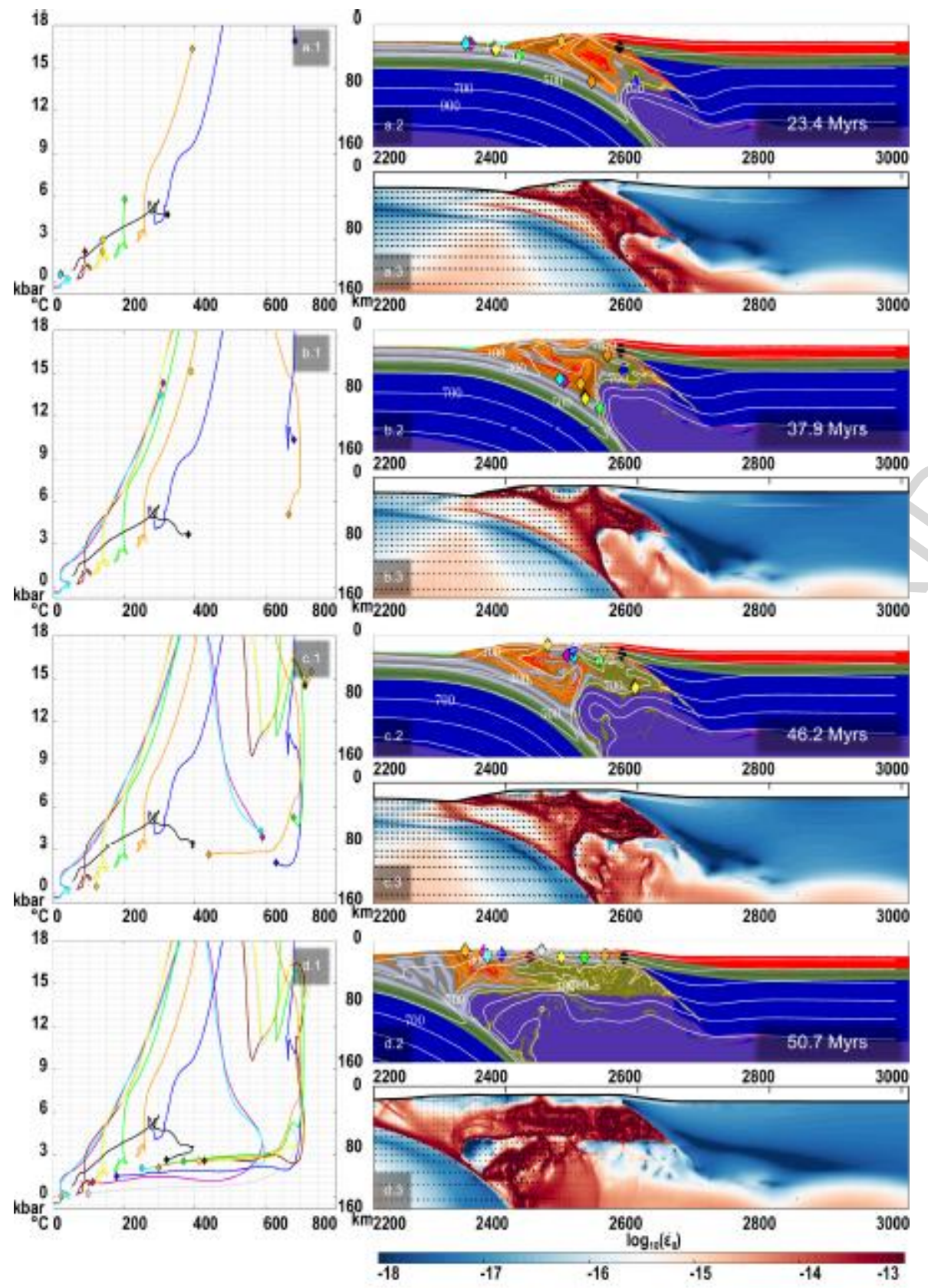

Figure 16 

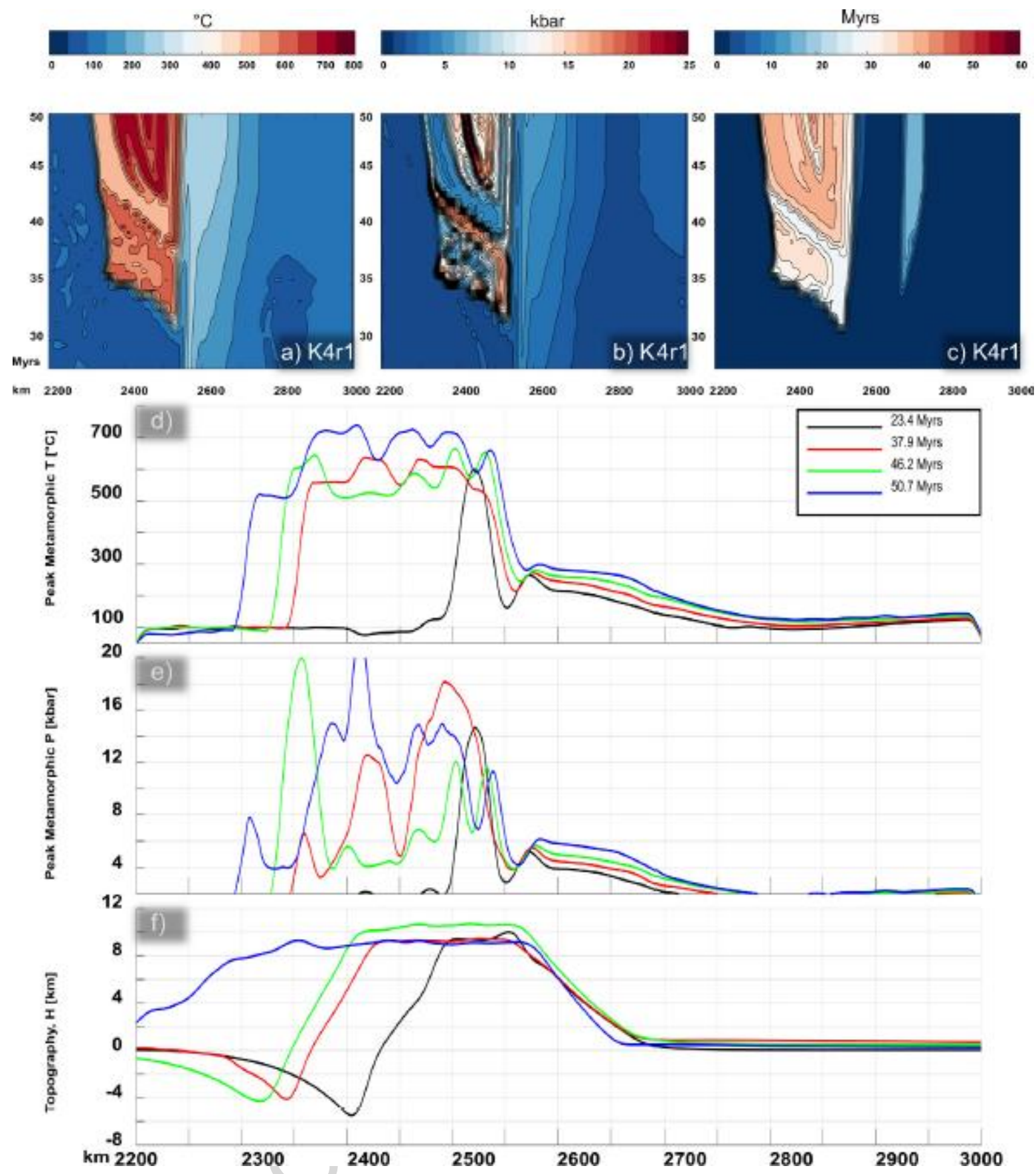

Figure 17 


\section{Highlights}

- We present 2D numerical experiments of post-subduction collision

- The rheology of the upper crust is systematically investigated

- The effects of surface processes and radiogenic heating rates were also explored

- Crust rheology and heat sources affect exhumation patterns and the collisional style

- Results are compared with natural examples of collisional systems (i.e. Himalaya) 